\title{
VARIABILITY IN ARABINOXYLAN, XYLANASE ACTIVITY AND XYLANASE INHIBITOR LEVELS IN HARD SPRING WHEAT
}

\author{
A Thesis \\ Submitted to the Graduate Faculty \\ of the \\ North Dakota State University \\ of Agriculture and Applied Science
}

\section{By}

Mihiri Marini Judith Mendis

\author{
In Partial Fulfillment \\ for the Degree of \\ MASTER OF SCIENCE
}

Major Program: Cereal Science

May 2012

Fargo, North Dakota 


\section{North Dakota State University}

Graduate School

Title

Variability in Arabinoxylan, Xylanase Activity and Xylanase Inhibitor Levels in

Hard Spring Wheat

\section{By}

Mihiri Marini Judith Mendis

The Supervisory Committee certifies that this disquisition complies with North Dakota State University's regulations and meets the accepted standards for the degree of

MASTER OF SCIENCE

SUPERVISORY COMMITTEE:

Dr. Senay Simsek

\section{Chair}

Dr. Paul Schwarz

Dr. Steven Meinhardt

Dr. Jae Ohm

Approved:

$\frac{06 / 05 / 2012}{\text { Date }}$

\begin{tabular}{l} 
Dr. Deland Myers \\
\hline Department Chair
\end{tabular}




\begin{abstract}
Arabinoxylans (AX), xylanase, and xylanase inhibitors have an important role in many cereal food processing applications. The effect of growing location $(\mathrm{L})$, genotype $(\mathrm{G})$, and their interactions $\left(\mathrm{L}^{*} \mathrm{G}\right)$ on $\mathrm{AX}$, apparent xylanase and apparent xylanase inhibition activities of Triticum aestivum xylanase inhibitor (TAXI) and xylanases inhibiting protein (XIP) of wheat was studied using six hard red spring wheat and six hard white spring wheat genotypes. Total AX content was largely dependent on $\mathrm{L}^{*} \mathrm{G}$. In bran, xylanase activity, $25 \%$ of the variability could be attributed to $\mathrm{L}^{*} \mathrm{G}$ interaction. Genotype contributed $72 \%$ to the variability in TAXI activity indicating TAXI activity in wheat bran is largely under genetic control. The bran TAXI level and XIP level varied by a factor of 700 and 3000, respectively, among genotypes. These results enable the industry to choose between different wheat varieties with varying xylanase activities to complement its intended use.
\end{abstract}




\section{ACKNOWLEDGEMENTS}

I sincerely appreciate and thank my advisor, Dr. Senay Simsek, for her invaluable advice, professional assistance, and guidance, and continuous encouragement during the course of this research project and in the preparation of this thesis.

My appreciation extends to all members of my graduate committee, Dr. Steven Meinhardt, Dr.

Paul Schwarz and Dr. Jae B. Ohm for their assistance, advice, and time contribution rendered to this thesis.

Dr. Kurt Gebruers and Dr. Jan Delcour are specially acknowledged for providing us with some of the enzymes and for their valuable support.

I also thank Ms. Kristin Whitney for the help extended to me during laboratory and equipment use and for valuable input.

I acknowledge the National Science Foundation Grant (\# HRD-0811239) to the NDSU Advance FORWARD program and the North Dakota Wheat Commission for funding this research.

I would also like to thank the faculty members, technical staff, and the office staff of the Department of Plant Sciences and the Cereal Science Graduate Program for their assistance and cooperation.

All the graduate students in the program and friends are sincerely acknowledged for their support and friendship throughout this research.

A special thanks to my parents, Mr. Cycil Mendis and Mrs. Hilda Mendis and my brother, Mr. Praneeth Mendis for their love and encouragement which has helped me immensely in all aspects of my life.

My heartfelt gratitude and appreciation goes to my husband, Mr. Dulan Samarappuli for his love, support and understanding that has made the fulfillment of this work possible. 


\section{TABLE OF CONTENTS}

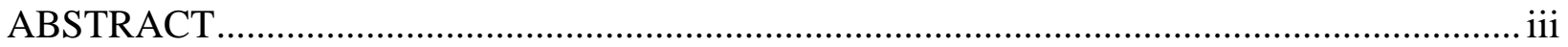

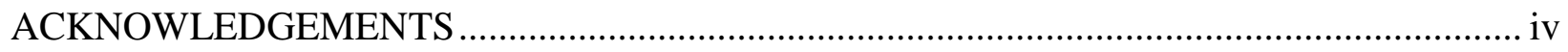

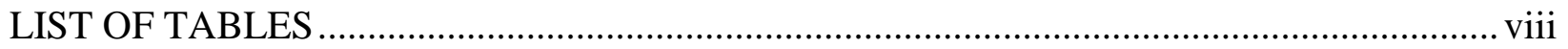

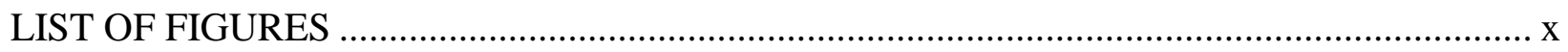



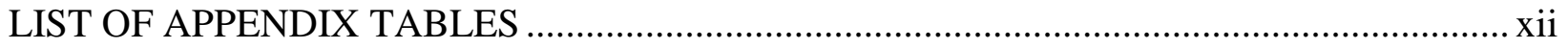

1. GENERAL INTRODUCTION .................................................................................. 1

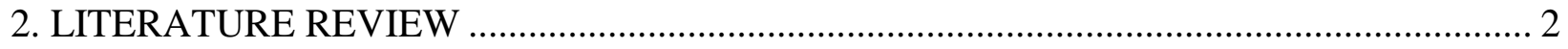

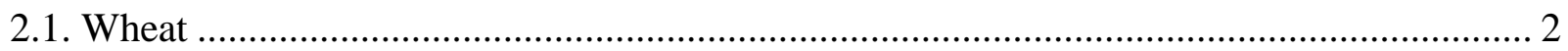

2.1.1. Hard and soft wheat .................................................................................... 2

2.1.2. Red and white wheat.................................................................................... 3

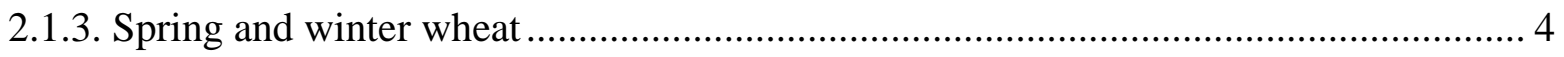

2.2. Plant Cell Wall and Arabinoxylans $(\mathrm{AX})$................................................................ 4

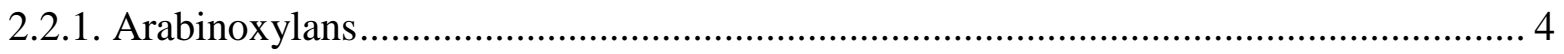

2.2.2. Endo- $\beta-(1,4)-D-x y l a n a s e s$ (xylanases) …............................................................... 5

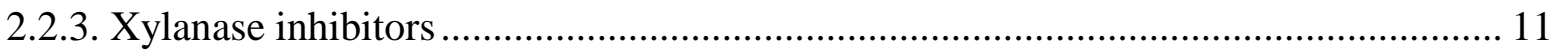

2.2.3.1. Triticum aestivum xylanase inhibitor, TAXI ............................................. 13

2.2.3.2. Xylanases inhibiting protein, XIP ........................................................... 14



2.2.3.1. Azurine-crosslinked arabinoxylan (Xylazyme AX) assay procedure.................. 16

2.2.3.2. Dinitro salicylic acid (DNS) assay procedure .......................................... 17

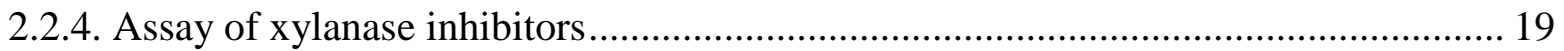

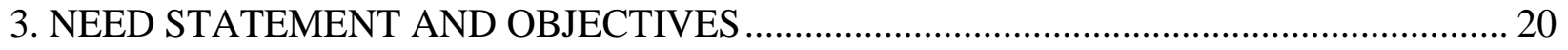

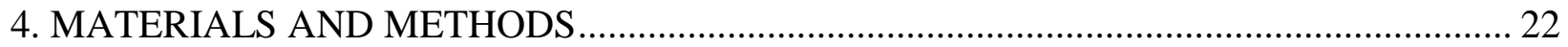






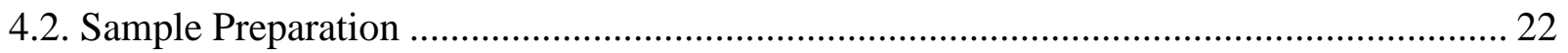

4.3. Determination of Total Arabinoxylans (TOT-AX) and Arabinose to Xylose Ratio (A/X) of Wheat Bran Using Gas Chromatography (GC) …………………………………….... 23

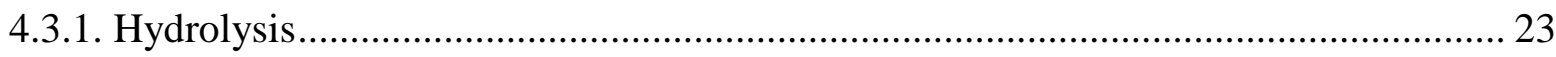

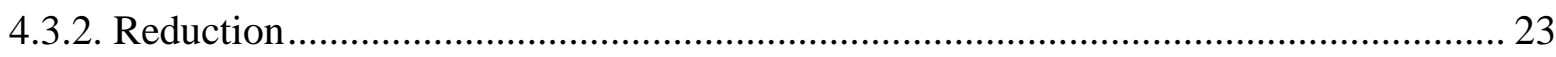

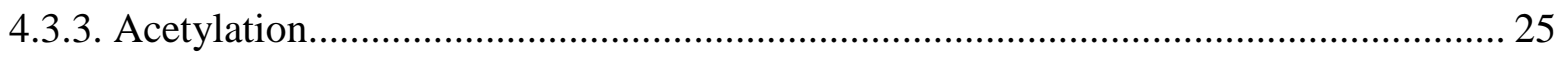

4.4. Determination of Arabinose Substitution Pattern Using Proton Nuclear Magnetic

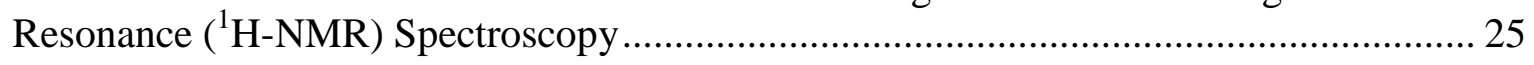

4.5. Determination of Apparent Xylanase Activity ........................................................... 26

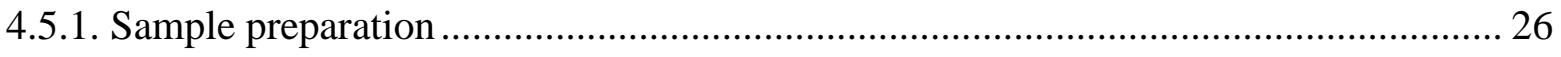

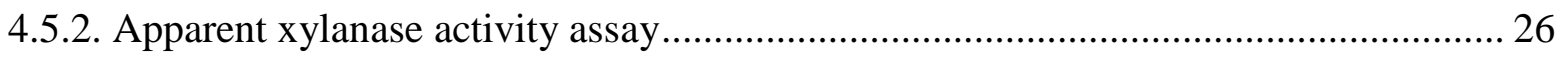

4.6. Determination of Apparent Xylanase Inhibition Activity of TAXI and XIP.................... 28

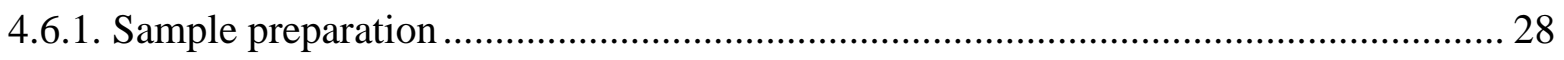

4.6.2. Apparent xylanase inhibition activity assay .............................................................. 28

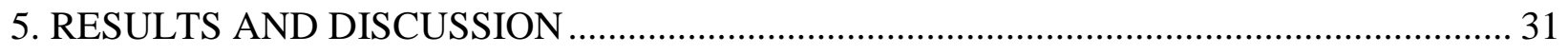

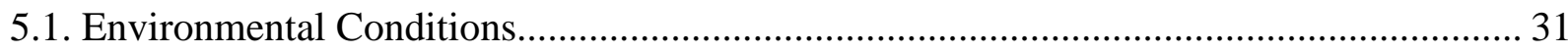

5.2. Total Arabinoxylans (TOT-AX) and Arabinose to Xylose Ratio (A/X) of Wheat Bran... 32

5.3. Substitution Pattern of AX Using ${ }^{1}$ H-NMR ....................................................................... 35

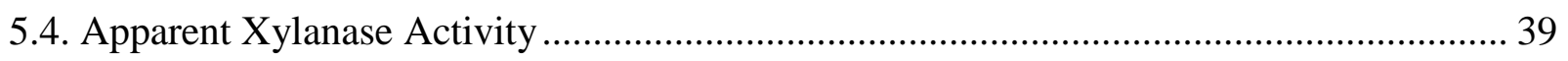

5.5. Apparent Xylanase Inhibition Activity of TAXI and XIP ............................................... 43

5.6. Correlation between Xylanase Activity, Xylanase Inhibition Activity, and Other Parameter .............................................................................................................. 51

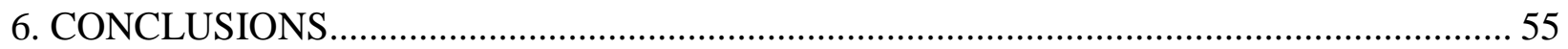

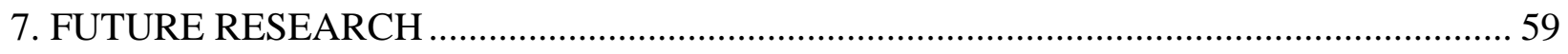

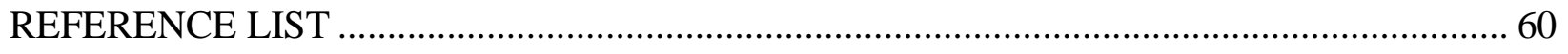




\section{LIST OF TABLES}

$\underline{\text { Table }}$

$\underline{\text { Page }}$

2.1. Basic comparison between the xylanase of $\mathrm{GH} 10$ and 11 with respect to their origin, molecular mass, conformation, and products............................................................. 8

2.2. Xylanase activity found in flour and bran of different cereals. ..................................... 10

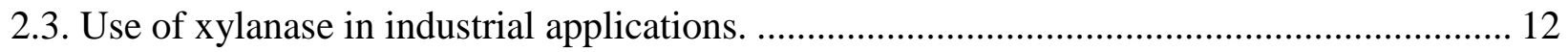

2.4. Level of TAXI type xylanase inhibitors in different cereals. ........................................ 14

2.5. Inhibition specificity of XIP and TAXI towards GH 10 and GH 11 family xylanase.......... 15

2.6. Comparison between the Xylazyme AX assay and DNS assay. .................................... 18

4.1. Genotype, class, origin and pedigree of hard spring wheat samples. .............................. 24

5.1. Precipitation and temperature for the growing season at Carrington, and Prosper, North Dakota in 2008.

5.2. Average total arabinoxylans (TOT-AX) and arabinose to xylose (A/X) ratio of wheat bran of 12 hard spring wheat genotypes grown at three locations, Carrington, Casselton,

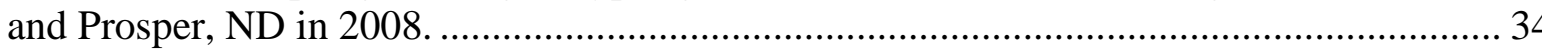

5.3. Combined Analysis of Variance (genotype fixed; location random) for TOT-AX (\% d.m.) and $\mathrm{A} / \mathrm{X}$ ratio.

5.4. Proportions (\%) of mono-, di-, and neighboring di- substituted xylose in water extractable arabinoxylans calculated using ${ }^{1} \mathrm{H}$ - NMR spectral data for four hard spring wheat genotypes grown in Prosper, Casselton and Carrington, ND in 2008.

5.5. Apparent xylanase activity in bran, flour and whole meal for 12 hard spring wheat genotypes grown at three different locations, Carrington, Casselton, and Prosper, ND in 2008

5.6. Combined Analysis of Variance (genotype fixed; location random) of bran and whole meal xylanase activity.

5.7. Combined Analysis of Variance (genotype fixed; location random) of bran TAXI, XIP and flour XIP activity levels.

5.8. Mean genotype apparent xylanase activity, apparent TAXI activity, and apparent XIP activity in bran and flour in three locations, Carrington, Casselton and Prosper, ND in 2008 . 
5.9. Correlation coefficients among parameters ${ }^{\mathrm{a}}$ tested in wheat genotypes in Carrington, ND

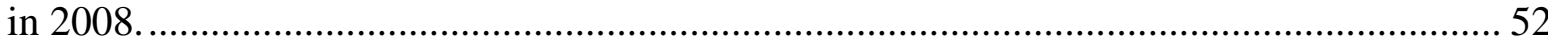

5.10. Correlation coefficients among parameters ${ }^{\mathrm{a}}$ tested in wheat genotypes in Casselton, ND

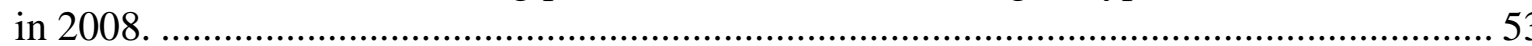

5.11. Correlation coefficients among parameters ${ }^{\mathrm{a}}$ tested in wheat genotypes in Prosper, ND in 2008 


\section{LIST OF FIGURES}

$\underline{\text { Figure }}$

$\underline{\text { Page }}$

2.1. Wheat grain showing its component tissues................................................................. 3

2.2. Structure of arabinoxylan (AX) and the sites of attack by xylanolytic enzymes involved in its degradation.

2.3. General mechanism for catalytic hydrolysis of xylan backbone by xylanase of GH 10 and 11.

2.4. Flow diagram representation of the basic steps in xylanase assay procedure using Xylazyme AX tablets.

4.1. Schematic flow diagram illustrating the steps in apparent xylanase activity assay procedure.

4.2. Schematic flow diagram illustrating the steps in apparent xylanase inhibition assay procedure. 30

5.1. Proton nuclear magnetic resonance spectrum of the WE-AX of wheat bran.

5.2. Contribution (\%) of genotype (G), location (L), interaction between $\mathrm{L}$ and $\mathrm{G}\left(\mathrm{L}^{*} \mathrm{G}\right)$, replicates by $\mathrm{L}(\operatorname{Rep}(\mathrm{L}))$ and the residual variability that cannot be explained by above variables $(\mathrm{R})$ to the apparent xylanase activity of wheat bran (a) and whole meal (b).

5.3. Variability of TAXI activity in bran (a) and flour (b) of different genotypes at different locations (Carrington, Casselton, and Prosper).

5.4. Variability of XIP activity in bran (a) and flour (b) of different genotypes at different locations (Carrington, Casselton, and Prosper).

5.5. Contribution (\%) of genotype $(\mathrm{G})$, location $(\mathrm{L})$, interaction between $\mathrm{L}$ and $\mathrm{G}(\mathrm{L} * \mathrm{G})$, replicates by $\mathrm{L}(\operatorname{Rep}(\mathrm{L}))$ and the residual variability that cannot be explained by above variables $(\mathrm{R})$ to the variation in apparent TAXI activity of wheat bran.

5.6. Contribution (\%) of genotype $(\mathrm{G})$, location $(\mathrm{L})$, interaction between $\mathrm{L}$ and $\mathrm{G}(\mathrm{L} * \mathrm{G})$, replicates by $L(\operatorname{Rep}(\mathrm{L}))$ and the residual variability that cannot be explained by above variables (R) to the variation in apparent XIP activity of wheat bran (a) and flour (b)....... 50

6.1. Overall representation of this study.... 


\section{LIST OF ABBREVIATIONS}

$\begin{array}{ll}\text { AX } & \text { Arabinoxylan } \\ \text { A/X ratio } & \text { Arabinose to xylose ratio } \\ \text { BSA } & \text { Bovine serum albumin } \\ \text { d.m. } & \text { Dry matter } \\ \text { HRSW } & \text { Hard red spring wheat } \\ \text { HWSW } & \text { Hard white spring wheat } \\ \text { InU } & \text { Inhibition unit } \\ \text { TOT-AX } & \text { Total AX } \\ \text { TAXI } & \text { Triticum aestivum xylanase inhibitor } \\ \text { TLXI } & \text { Thaumatin like xylanase inhibitor } \\ \text { WE-AX } & \text { Water-extractable AX } \\ \text { WU-AX } & \text { Water-unextractable AX } \\ \text { XIP } & \text { Xylanases inhibiting protein }\end{array}$




\section{LIST OF APPENDIX TABLES}

$\underline{\text { Appendix }}$

$\underline{\text { Page }}$

A.1. Bartlett's test for homogeneity of variance.

A.2. Location mean apparent xylanase activity, apparent TAXI activity and apparent XIP activity for 12 hard spring genotypes grown in Carrington, Casselton and Prosper, ND in 2008 . 


\section{GENERAL INTRODUCTION}

Arabinoxylans (AX), xylanase, and xylanase inhibitors have an important role in many cereal food processing applications including breadmaking (Courtin and Delcour, 2002), glutenstarch separation (Frederix et al., 2004b), refrigerated dough (Poulsen and Soerensen, 2001; Simsek and Ohm, 2009; Courtin et al., 2005) and increasing the feed conversion of animal feeds (Bedford and Schulze, 1998). Microbial xylanases are routinely added in some food processes to hydrolyze AX. However, the effectiveness of these additions are influenced by grain associated xylanase, and xylanase inhibitors occurring naturally in wheat kernels in variable amounts in different cultivars (Gebruers et al., 2010; Bonnin et al., 2005).

The present research is carried out to find the effect of genotype, growing location, and genotype growing location interactions on the xylanase and xylanase inhibition activities, waterextractable AX level and arabinose substitution pattern in twelve different hard spring wheat genotypes, which included six hard red spring wheat (HRSW) and six hard white spring wheat (HWSW) genotypes grown at three locations, ND. The experimental design was a randomized complete block design with two replicates for each location. The results of this study may help to determine the effect of genotype and location on the above mentioned parameters of HRSW and HWSW genotypes. 


\section{LITERATURE REVIEW}

\subsection{Wheat}

Wheat is one of the dominant grains produced in the world. It is a grass, which belongs to the family Poaceae (syn. Gramineae). It is considered a "cereal" as it is grown primarily for its grain (or caryopsis) (Gooding, 2009). Although the term 'wheat' describes a number of species and subspecies in the genus Triticum the most important are the hexaploid common wheat ( $T$. aestivum subsp. aestivum), also known as the bread wheat, which account for more than $90 \%$ of the world wheat production. However, within this subspecies not all varieties are equally suitable for bread making. Some genotypes have been shown to possess more desirable qualities than others. Mostly, these qualities are inherited and have led to common wheat being generally classified on the basis of their seed coat color, endosperm texture, dough strength and sowing season. The longitudinal and cross sectional view of the wheat kernel is shown in Figure 2.1. During cereal milling, the starchy endosperm is reduced in its particle size to produce flour (Delcour and Hoseney, 2010a). The outer layers of the grain from the pericarp to aleurone layer are removed to produce bran. The germ is also separated from the endosperm and usually collected in the bran fraction.

\subsubsection{Hard and soft wheat}

Wheat varieties have been classified based on the force required when milling (Gooding, 2009). The harder the wheat, the greater the force required. The factors governing these differences in wheat endosperm hardness are not clearly understood, however, the presence and absence of friabilin, a surface protein complex found on starch granules is thought to be an important contributor (Delcour and Hoseney, 2010b; Gooding, 2009). It has two main isoforms, puroindolin $\underline{a}$ and puroindolin $\underline{b}$. The theory is that puroindolins control the interaction of starch 
granules with gluten by weakening the interaction. The expression of both isoforms results in softness. The mutation in either of the isoforms results in hardness (Gooding, 2009). Hard wheat is preferred in bread making as it is easier to mill and has higher water holding capacity, which makes it suitable to be used in more moist products than soft wheat.

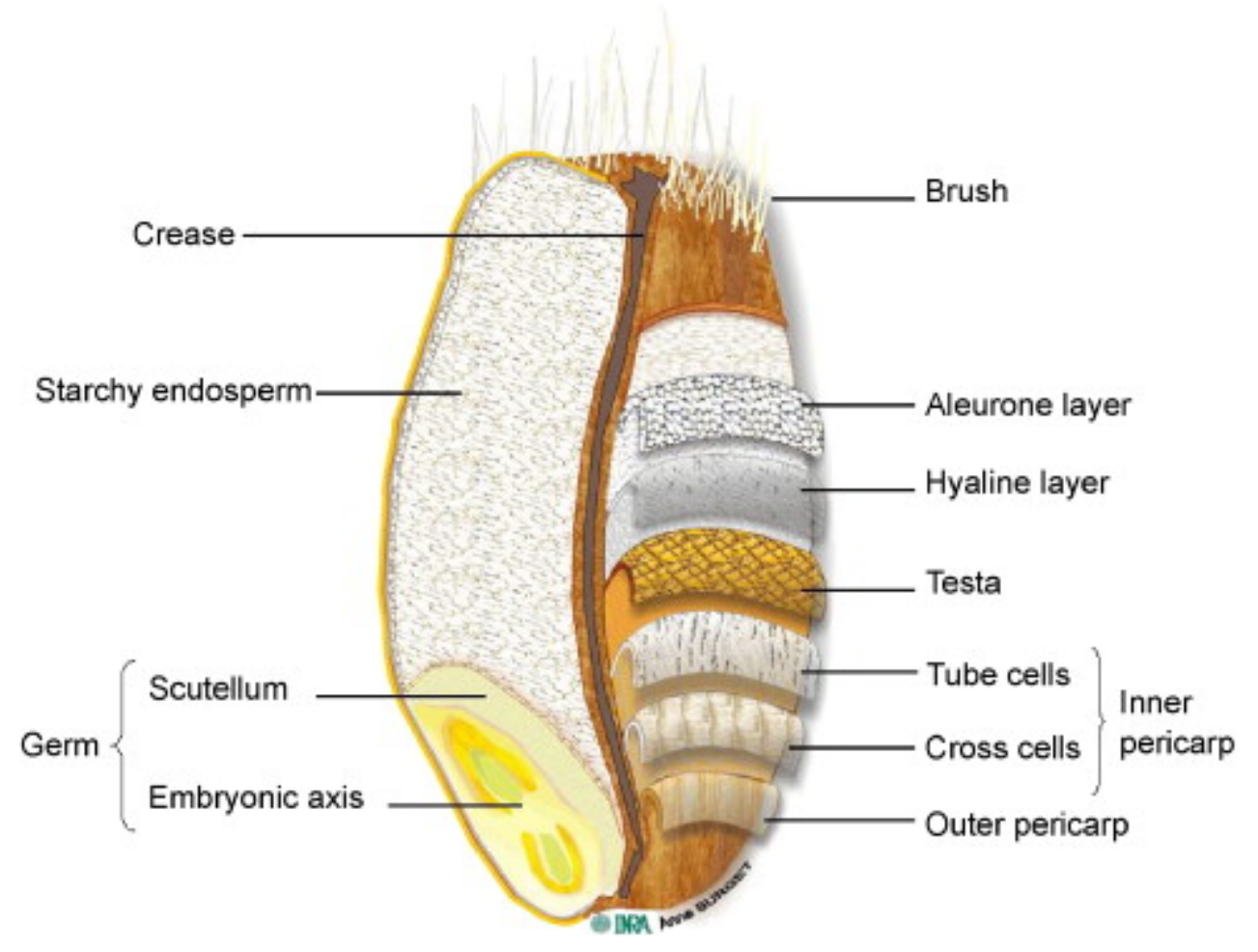

Figure 2.1. Wheat grain showing its component tissues. Reprinted from Saulnier et al. (2007).

\subsubsection{Red and white wheat}

This classification is based on the intensity of the red pigmentation (phiobaphene) on the seed coat (Gooding, 2009). This red color intensity is mainly determined by three functionally equivalent genes. Red varieties carry more of the dominant alleles which are responsible for red color. The red color intensity increases as the gene dosage increases. Red varieties are more dormant than white and are more suitable in environments prone to pre-harvest sprouting. 


\subsubsection{Spring and winter wheat}

Wheat is classified as winter or spring based on flowering responses to cold temperatures (Simmons et al., 1995). Winter wheat are usually planted in the fall which exposes the seedlings to cold temperatures during late fall and winter. Spring-types, however, do not require exposure to such cold temperatures for normal development and can be planted in spring.

\subsection{Plant Cell Wall and Arabinoxylans (AX)}

Plant cell walls are highly hydrated and gel like structure which surrounds the cell membrane (Vorwerk et al., 2004). Layers of long cellulose ( $\beta$-1-4 glucan) fibrils are interconnected with high molecular weight hemicellulose (typically AX in cereals) via hydrogen bonding and are embedded in a matrix of pectin. Cell wall of typical grass species contains $25 \%$ cellulose, $55 \%$ hemicellulose and $\sim 10 \%$ pectin. In wheat grain, AX consists of only about 4-7\% of the grain (Henry, 1985). However, it has a major contribution to the wheat cell wall by occurring up to $70 \%$ in wheat endosperm cell wall and $64 \%$ in the wheat bran cell wall (Fincher and Stone, 1986). Xylanase is the major enzyme involved in AX degradation. However, xylanases are subjected to inhibition by enzyme inhibitors, xylanase inhibitors. In the following section these three key players involved in the enzymatic system, the substrate, AX, the enzyme, xylanase, and the xylanase inhibitors will be discussed.

\subsubsection{Arabinoxylans}

In wheat, the major polymer of the cell wall is arabinoxylan (Saulnier et al., 2007). Even though they occur as a minor constituent of the grain, their unique physico-chemical properties allow them to have a considerable effect on cereals food industry, including bread making (Courtin and Delcour, 2002), gluten-starch separation (Frederix et al., 2004b),refrigerated dough syruping (Simsek and Ohm, 2009; Courtin et al., 2005) and in animal feeds (Bedford and 
Schulze, 1998). Furthermore, AX has been associated with beneficial health effects in patients with impaired glucose tolerance (Garcia et al., 2006). AX consists of a backbone of $\beta-(1,4)$ linked xylose residues, which are substituted with arabinose residues on the $\mathrm{C}(\mathrm{O})-2$ and/or $\mathrm{C}(\mathrm{O})$ 3 position (Dornez et al., 2009). Since AX are mainly composed of the pentose sugars xylose and arabinose, they are commonly referred to as pentosans. Phenolic acids such as ferulic acid can be ester linked on the $\mathrm{C}(\mathrm{O})-5$ position of arabinose. Under oxidative conditions, these ferulic acid residues undergo oxidative cross-linking between different ferulic acid residues forming inter/intra chain diferulic acid bridges (Geissman and Neukom, 1973). Ferulic acid can also function as a radical scavenger, thus it has a potential health benefit as an antioxidant (Mpofu et al., 2006). The structure of AX and AX degrading enzymes are shown in Figure 2.2.

Even though AX can be described using a general structure, two different classes of AX exist in wheat. They are the water-extractable AX (WE-AX), which account for about $25-30 \%$ of AX in wheat flour and water-unextractable AX (WU-AX), which account for the remainder of AX in wheat flour (Meuser and Suckow, 1986). Water-extractable AX are loosely bound to the cell wall surface (Mares and Stone, 1973). In contrast, water-unextractable AX are retained in the cell wall by covalent and non-covalent interactions with $\mathrm{AX}$ and protein, lignin and cellulose (Iiyama et al., 1994).

\subsubsection{Endo- $\beta-(1,4)-D-x y l a n a s e s$ (xylanases)}

Xylanase was originally termed pentosanase (Collins et al., 2005) and was given the official name endo- $\beta$-(1,4)-D-xylanase ( EC 3.2.1.8). However, commonly used synonyms

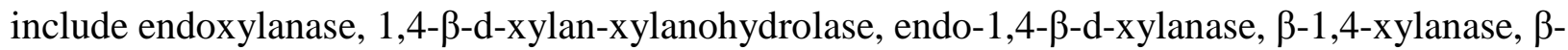
xylanase and xylanase (here after referred to as xylanase). Xylanases are the major enzymes involved in AX degradation. They cleave AX by internally hydrolyzing the 1,4- $\beta$-D-xylosidic 
linkage between xylose residues in the xylan backbone in a random manner (Figure 2.2.)

(Dornez et al., 2009; Collins et al., 2005).The complex and diverse nature of xylan has given rise to various xylanase. Thus, classification of xylanase is not simple and straight forward. Wong et al., (1988) classified xylanase based on their physicochemical properties. They classified xylanase in to two groups: those with low molecular weights ( $<30 \mathrm{kDa})$ and basic $\mathrm{p} I$, and those with higher molecular weight (>30 kDa) and acidic $\mathrm{p} I$. However, as new xylanases were discovered this classification was inadequate. Later a more complete classification was introduced, which was based on primary structure comparisons of the catalytic domain of the enzyme (Henrissat et al., 1989; Henrissat and Coutinho, 2001). This classification not only covers xylanase but covers glycosidase in general and has come to wide spread use. Initially, cellulases and xylanases were classified into six families A to F (Henrissat et al., 1989). However, this was updated to 77 families in 1999 (1-77) (Henrissat and Coutinho, 2001). At the time of writing, 130 Glycoside hydrolases (GH) (EC 3.2.1.x) families exist (Carbohydrate Active Enzyme CAZY server, 2012).

Over 290 xylanases have been identified (Fierens, 2007a), which have been grouped into different glycoside hydrolase (GH) families (5, 7, 8, 10, 11 and 43) (Dornez et al., 2009;Collins et al., 2005). Most of these xylanase are from fungal or bacterial origin. All plant xylanases identified so far belong to GH family 10, while most of the microbial xylanases are of GH family 10 or 11 (Simpson et al., 2003). Thus, within our research only xylanase of GH 10 and 11 are being discussed. Xylanases of family 10 are characterized by a (beta/alpha)- 8 -fold conformation and molecular masses that exceed $30 \mathrm{kDa}$, while xylanases of family 11 contain a jelly roll conformation and molecular masses of around 20 kDa (Biely et al., 1997; Kulkarni et al., 1999). The differences between xylanases from GH family 10 and 11 are given in Table 2.1. 


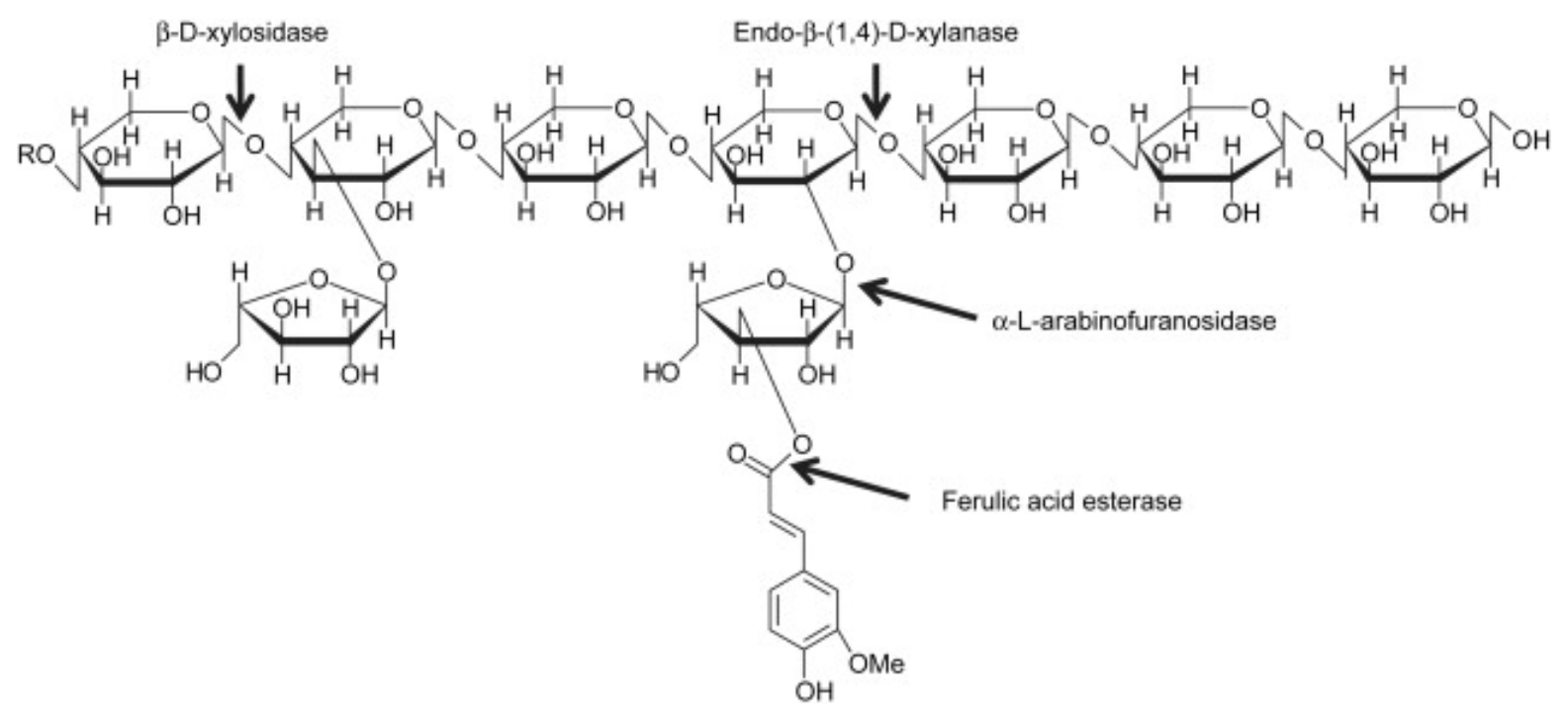

Figure 2.2. Structure of arabinoxylan (AX) and the sites of attack by xylanolytic enzymes involved in its degradation. The backbone of AX is composed of $\beta$-(1,4)-linked xylose residues, which can be substituted with arabinose residues on the $\mathrm{C}(\mathrm{O})-2$ and/or $\mathrm{C}(\mathrm{O})-3$ position. Ferulic acid can be esterified on the $\mathrm{C}(\mathrm{O})-5$ position of arabinose. Endo- $\beta-(1,4)-\mathrm{d}-\mathrm{xylanases}$ (EC 3.2.1.8) cleave the xylan backbone internally, $\beta$-d-xylosidases (EC 3.2.1.37) remove xylose monomers from the non-reducing end of xylo-oligosaccharides, $\alpha$-1-arabinofuranosidases (EC 3.2.1.55) remove arabinose substituents from the xylan backbone, and ferulic acid esterases (EC 3.1.1.73) remove ferulic acid groups from arabinose substituents (Dornez et al., 2009).

The general retaining mechanism for glycoside hydrolase family 10 and 11 has been described by many authors (Collins et al., 2005; McCarter and Stephen Withers, 1994; Rye and Withers, 2000; Zechel and Withers, 1999). Xylanase of both family 10 and 11 catalyze the hydrolysis of the xylosidic linkage with retention of anomeric configuration (Rye and Withers, 2000).The general reaction mechanism for this reaction is given in Figure 2.3. The reaction proceeds through a double displacement mechanism (Collins et al., 2005; McCarter and Stephen Withers, 1994; Rye and Withers, 2000; Zechel and Withers, 1999). 
Table 2.1. Basic comparison between the xylanase of GH 10 and 11 with respect to their origin, molecular mass, conformation, and products (Collins et al., 2005; Biely et al., 1997; Kulkarni et al., 1999).

\begin{tabular}{lll}
\hline & \multicolumn{2}{c}{ Xylanase } \\
\cline { 2 - 3 } Origin & GH family 10 & GH family 11 \\
\cline { 2 - 3 } & All plant xylanase & Microbial \\
& Microbial & \\
Molecular mass & Higher molecular mass $(>30 \mathrm{kDa})$ & Lower molecular mass $(\sim 20 \mathrm{kDa})$ \\
Conformation & $(\beta / \alpha)_{8}$ barrel fold & $\beta$-jelly roll \\
Products & Smaller oligosaccharides & Larger oligosaccharides \\
\hline
\end{tabular}

Two carboxylic acid residues in the active site are involved in formation of the enzymesubstrate intermediate; one acts as an acid by protonating the substrate, while other performs a nucleophilic attack. With the departure of the leaving group, a covalent glycosyl-enzyme intermediate is formed (inversion from $\beta$ to $\alpha$ ). In the second step, the first carboxylic acid acts as a base and abstracts a proton from a water molecule. The nucleophilic water molecule then attacks the anomeric carbon of the xylan. This leads to the formation of the second intermediate state in which the anomeric carbon undergoes an oxocarbonium-ion-like transition state (inversion from $\alpha$ to $\beta$ ). This proceeds with the release of the substrate with retention of the original conformation at the anomeric center.

Hydrolysis of AX by xylanase causes a decrease in the degree of polymerization in the AX and produces AX oligosaccharides, xylobiose and xylose, with retention of their conformation (Dekker and Richards, 1976; Reilly, 1981; Delcour and Hoseney, 2010c). 


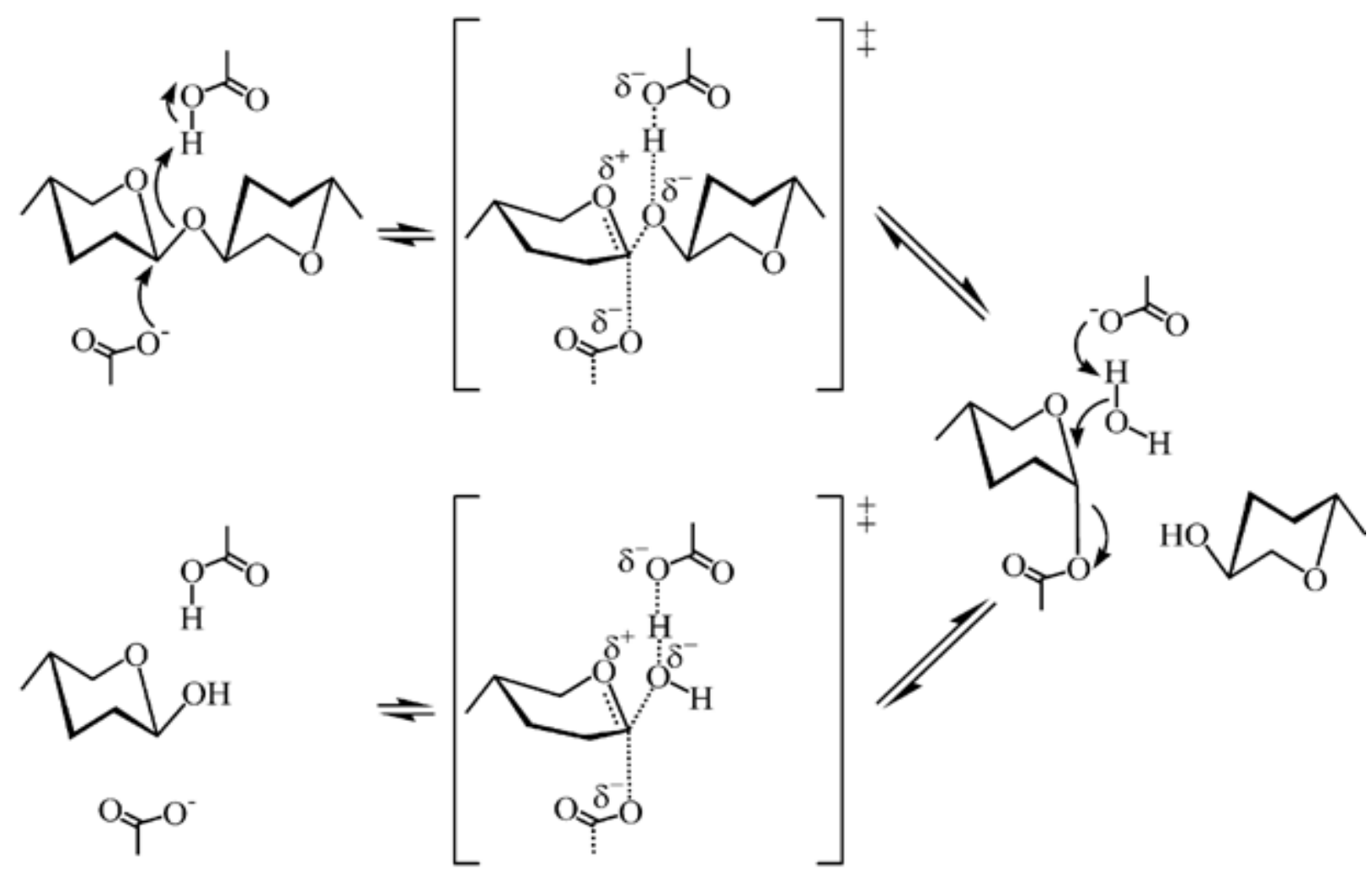

Figure 2.3. General mechanism for catalytic hydrolysis of xylan backbone by xylanase of GH 10 and 11. Reprinted from Rye and Withers (2000).

Most xylanases are produced by bacteria and fungi, but they are also present in plants, insects, snails, crustaceans, marine algae, and protozoa (Dekker and Richards, 1976). However, xylanases are naturally found on cereal grains and large portion of these grain-associated xylanases are of microbial origin, resulting from the microbes residing on the kernel surface, whereas a smaller portion is of plant origin, occurring inside the kernel (endogenous xylanase) (Dornez et al., 2006a). Induction of xylanase expression in microorganisms occurs when there are low molecular mass fragments of xylan are present (Tomme et al., 1995). The repression of xylanase occurs when more readily available carbon sources are present (Kulkarni et al., 1999). Microbes secrete xylanase to degrade the plant cell wall and penetrate the cell wall. However, plants also produce endogenous xylanase. They play a role in mobilizing reserves from storage 
organs, remodeling of plant cell wall during cell growth and development (Igawa et al., 2004), degradation of aleurone and endosperm cell walls to make starch and protein more accessible for amylases and proteases during seed germination (Benjavongkulchai and Spencer, 1986), secondary cell wall metabolism during vascular bundle development (Suzuki et al., 2002), and softening of fruits during fruit ripening (Chen and Paull, 2003). The amount of xylanases found in different cereals is shown in Table 2.2. The distribution of xylanase across the grains is not uniform, with higher levels in bran than in endosperm.

Table 2.2. Xylanase activity found in flour and bran of different cereals.

\begin{tabular}{llc}
\hline Cereal species & \multicolumn{2}{l}{ Xylanase activity $\left(\mathrm{EU}^{\mathrm{a}} / \mathrm{g}\right)^{\mathrm{b}}$} \\
\cline { 2 - 3 } & Flour & Bran \\
\hline Durum wheat (Triticum durum) & $0.95 \mathrm{a}$ & $3.59 \mathrm{a}$ \\
Barley (Hordeum vulgare) & $0.33 \mathrm{bc}$ & $1.22 \mathrm{~b}$ \\
Common wheat (Triticum aestivum) & $0.06 \mathrm{c}$ & $0.54 \mathrm{bcd}$ \\
Oats (Avena sativa) & $0.49 \mathrm{~b}$ & $0.89 \mathrm{bc}$ \\
Rye (Secale cereale) & $0.07 \mathrm{c}$ & $0.29 \mathrm{~cd}$
\end{tabular}

${ }^{\mathrm{a}} \mathrm{EU}=$ enzyme unit. One enzyme unit is the amount of enzyme needed to increase the extinction at $590 \mathrm{~nm}$ by 1.0 per hour of incubation under the conditions of the Xylazyme-AX assay (Dornez et al., 2006a).

${ }^{\mathrm{b}}$ Values with the same letter within a column are not statistically different from each other (pvalue $>0.05)$.

(Adapted from Dornez et al. (2009))

By the year 2001 the global market for industrial enzymes was an ca. \$2.6 billion industry (Collins et al., 2005). Grain processing enzyme sector accounts for about $25-28 \%$ of this 
total enzyme sales. Microbial xylanases are frequently used in many industries to alter the functionality of AX in biotechnological processes such as bread making, gluten-starch separation, beer production, paper and pulp production and animal feed industry (Christophersen et al., 1997; Courtin and Delcour, 2002; Courtin et al., 1999; Rouau and Surget, 1998). In recent years, xylanases have gained increased attention due to its increase use in industrial applications. In the search for xylanase in the United States Patent and Trade Mark Office website yields 1768 patents for the time period of 1976 to 2012 (United States Patent and Trademark Office, 2012). The uses of xylanase in some of the industrial applications are listed in Table 2.3.

\subsubsection{Xylanase inhibitors}

Chemicals that inhibit xylanase include sulfhydryl reagents, several metal ions, glycerol, and ethanediol (Dekker and Richards, 1976). Moreover, xylanases are subjected to product inhibition by products of AX degradation such as xylose, arabinose and xylotriose. In wheat, three proteinaceous xylanase inhibitors have been identified to date: TAXI (Triticum aestivum xylanase inhibitor) (Debyser et al., 1999), XIP (xylanases inhibiting protein) (McLauchlan, 1999), and TLXI (thaumatin like xylanase inhibitor) (Fierens, 2007a). The content of these inhibitors are considerably higher in wheat (Dornez et al., 2009) and considerable differences exist in their amount between different cereal types and varieties (Gebruers et al., 2010). Apart from these cereal proteinaceous inhibitors, two non-cereal xylanase inhibitors of microbial origin have also been identified. They are Pepstatin A of Actinomycetes (Vathipadiekal and Rao, 2004) and alkalo thermophilic Bacillus inhibitor (ATBI) (Dash et al., 2001).

Xylanase inhibitors in plants have been suggested to play a role of plant defense (Dornez et al., 2010). This is mainly supported by the fact that TAXI, XIP or TLXI do not inhibit endogenous, wheat xylanase, but inhibit microbial xylanase. Other evidence include the special 
distribution of xylanase inhibitors in grain, mainly occurring in the outer kernel layer, structural homology with defense related proteins, induction by biotic and abiotic stress, temporal distribution of xylanase inhibitors in grain during development and germination, etc.

Table 2.3. Use of xylanase in industrial applications. Adapted from Bhat (2000).

\begin{tabular}{|c|c|c|}
\hline Enzyme & Function & Application \\
\hline Endoxylanases, xylan & Modification of cereal & Improvement in the texture, \\
\hline \multirow{2}{*}{ debranching enzymes } & arabinoxylan and production of & quality and shelf life of \\
\hline & arabinoxylo-oligosaccharides & bakery products \\
\hline Xylanases and & Hydrolysis of arabinoxylan and & Separation and isolation of \\
\hline \multirow[t]{2}{*}{ endoglucanases } & starch & starch and gluten from wheat \\
\hline & & flour \\
\hline \multirow[t]{4}{*}{$\beta$-Glucanase and xylanase } & Hydrolysis of cereal $\beta$-glucans & Improvement in the feed \\
\hline & and arabinoxylans, decrease in & digestion and absorption, \\
\hline & intestinal viscosity and release & weight gain by broiler \\
\hline & of nutrients from grains & chickens and hens \\
\hline Hemicellulase with high & Increase the nutritive quality of & Reduction in the cost of pig \\
\hline \multirow[t]{2}{*}{ xylanase activity } & pig feeds & feeds and the use of less \\
\hline & & expensive feeds for pigs \\
\hline Xylanases, mananases, $\beta$ - & Hydrolysis of re-precipitated & Bio-bleaching of kraft pulps; \\
\hline xylosidase and $\alpha-\mathrm{L}-$ & xylan or removal of xylan from & reduction in chlorine \\
\hline \multirow[t]{3}{*}{ arabinofuranosidase } & lignin-carbohydrate complexes; & requirement in subsequent \\
\hline & removal of glucomannan & bleaching and environmental \\
\hline & & pollution \\
\hline
\end{tabular}


Xylanase inhibitors have an important impact on the biotechnological applications of wheat. Microbial xylanases are routinely added to wheat grains during grain processing to achieve the desired level of AX degradation. However, the efficiency and functionality of these microbial xylanase are affected by the amount of inhibitors naturally occurring within the grain, and the sensitivity of the microbial xylanases to these inhibitors. The increase in bread loaf volume upon addition of xylanase was shown to be abolished by the addition of TAXI (Debyser et al., 1999). In gluten-starch separation, depending on the type of xylanase being used, the dosage of the xylanase being added has to be increased approximately four times to obtain the same positive effect on gluten agglomeration and batter viscosity (Frederix et al., 2004a). Endogenous xylanase inhibitors have been found to negatively affect the effectiveness of added xylanase in pig and poultry feeds (Soerensen et al., 2004). Thus, it is important to identify wheat varieties with low xylanase inhibition levels. However, xylanase inhibitors have positive effects on some biotechnological processes, too. Dough syruping is an undesirable phenomenon associated with refrigerated dough. Addition of TAXI type inhibitors have been shown to reduce syruping up to $50 \%$ after 10 days of storage at $10{ }^{\circ} \mathrm{C}$ (Poulsen and Soerensen, 2001).

2.2.3.1. Triticum aestivum xylanase inhibitor, TAXI. First evidence for the presence of xylanase inhibitors in wheat was observed in 1997 by Debyser et al. (1997). As they used unmalted wheat adjunct in brewing, they observed a lower increase in WE-AX during mashing than in the presence of $100 \%$ barley malt wort. However, this effect was cancelled if the wheat was boiled. This indicated that this effect was due to the inhibition of barley malt xylanase by a heat-labile water extractable wheat protein. Debyser et al. (1999) purified this inhibitor from wheat flour and gave the name TAXI (for Triticum aestivum xylanase inhibitor). However, later on TAXI type inhibitors were purified from barley (Hordeum vulgare xylanase inhibitor, HVXI) (Goesaert 
et al., 2001), Durum wheat (Triticum durum xylanase inhibitor, TDXI) (Goesaert et al., 2003b) and Rye (Secale cereale xylanase inhibitor, SCXI) (Goesaert, 2002). Approximate levels of TAXI type xylanase inhibitors in these cereals are presented in Table 2.4.

Table 2.4. Level of TAXI type xylanase inhibitors in different cereals.

\begin{tabular}{ll}
\hline Cereal & Level of TAXI $^{\mathrm{a}}(\mathrm{ppm})$ \\
\hline Wheat (Triticum aestivum) & 38 \\
Barley (Hordeum vulgare) & $4-5$ \\
Durum wheat (Triticum durum) & 11 \\
Rye (Secale cereale) & 30
\end{tabular}

${ }^{\mathrm{a}}$ The levels presented are approximate values and are based on TAXI that could be isolated using affinity chromatography with immobilized Bacillus subtilis xylanase only. The values can vary depending on the cultivar. (Adapted from Goesaert et al. (2004))

Genes for TAXI type proteins in wheat are expressed in different plant tissues in different development stages (Goesaert et al., 2004). The outer layer of wheat grains has been found to contain higher levels of TAXI than the rest of the grain (Bonnin et al., 2005). TAXI is expressed when the plant is under stress due to pathogens (e.g. Fusarium graminearum infection) and drought (Fierens et al., 2003). TAXI occurs in two different isoforms known as TAXI-I and TAXI-II (Gebruers et al., 2001). Six different isoforms of TAXI-I has been identified in wheat, while for TAXI-II only one predominant isoform has been identified (Fierens, 2007a). 2.2.3.2. Xylanases inhibiting protein, XIP. A second type of xylanase inhibition proteins was identified in wheat by McLauchlan (1999). Levels of XIP inhibitors in wheat were 2 to 3 times higher than TAXI. Bonnin et al. (2005) measured XIP levels in 20 French wheat cultivars and found that the levels varied among 210- 560 ppm among cultivars. Dornez et al. (2006c) 
observed that XIP content in wheat flour was 1.2 times lower than in the whole meal indicating that XIP is concentrated in the outer layer of the grain. Also, a large part of XIP variability between different wheat cultivars in different environments could be attributed to genotype (69\%). Furthermore, the XIP levels in wheat were not correlated to TAXI levels (Dornez et al., 2008). Inhibition specificities of XIP and TAXI are listed in Table 2.5.

Table 2.5. Inhibition specificity of XIP and TAXI towards GH 10 and GH 11 family xylanase.

\begin{tabular}{lll}
\hline GH family & GH family 10 & GH family 11 \\
\hline Inhibitor & XIP (fungal GH 10 xylanase & XIP (fungal GH 11 xylanase only) \\
& only) & TAXI (both fungal and bacterial GH 11 \\
& & xylanase) \\
Example & Penicillium purpurogenum & Bacillus subtilis xylanase \\
& xylanase & \\
\hline
\end{tabular}

XIP inhibits both GH 10 and GH 11 xylanases, but only those of fungal origin (Dornez et al., 2009). On the other hand, TAXI type inhibitors inhibit xylanases of fungal and bacterial origin from GH family 11 and not GH family 10 (Goesaert et al., 2001). This understanding about the inhibition specificity of the xylanase inhibitors has been exploited to interpret the amount of each inhibitor in the presence of each other. Based on this fact, Dornez et al. (2006a) used two different xylanases; Bacillus subtilis xylanase (GH 11) of bacterial origin to determine TAXI activity; and Penicillium purpurogenum xylanase (GH 10) of fungal origin to determine XIP activity in wheat grains (Dornez et al., 2006a). In wheat, endoxylanase activities are largely dependent on variety and weather condition prior to harvesting (Dornez et al., 2006b). However, 
endoxylanase inhibitor levels are less dependent on climatological factors and variability in varieties is mainly due to genetic factors.

\subsubsection{Assay of xylanase}

Different assay procedures are being used to measure xylanase levels in cereals. These involve detection of reducing sugars released from the substrate upon hydrolysis by the enzyme, dye released from covalently dyed arabinoxylans, decrease of viscosity of suitable substrate solutions and decrease of turbidity of appropriate substrate suspensions (Dong, 2010). Two of the common methods are discussed here.

2.2.3.1. Azurine-crosslinked arabinoxylan (Xylazyme AX) assay procedure. The most common method in use today is the endo-1-4, $\beta$-D-xylanase assay procedure (Xylazyme AX method) (Megazyme, Ireland) which uses azurine-crosslinked arabinoxylan (Xylazyme AX) tablets. The over view of the assay procedure are summarized in Figure 2.4.

Xylazyme AX tablet (non-soluble in aqueous media)

$$
\text { Xylanase }
$$

Intact Xylazyme AX tablet particles (non-soluble) +

smaller fragments of Xylazyme AX (soluble)

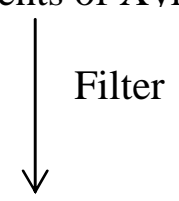

Smaller fragments of Xylazyme AX (soluble) comes to the filtrate

$$
\downarrow
$$

Measure filtrate absorbance at $590 \mathrm{~nm}$

Figure 2.4. Flow diagram representation of the basic steps in xylanase assay procedure using Xylazyme $\mathrm{AX}$ tablets. 
The method is based on the amount of Xylazyme AX particles (soluble) released into the solution due to the action of xylanases acting on the original Xylazyme AX molecule (nonsoluble). Thus, the method is not directly quantifying the amount of xylanases present in a given sample, but is indirectly measuring the xylanase enzyme activity. However, it is the common practice to quantify enzymes based on their activity rather than the actual amount of enzyme present.

2.2.3.2. Dinitro salicylic acid (DNS) assay procedure. The other method used to determine xylanase activity is DNS assay procedure described by Miller (1959). As xylanase acts on AX, it releases xylan residues which are reducing sugars. Thus, in the presence of oxidizing agents such as 3,5-dinitrosalicylic acid, xylans can undergo oxidation while 3,5-dinitrosalicylic acid is reduced to 3- amino-5-nitrosalicylic acid, which is a colored molecule and can be quantified using spectrophotometer at 550-575 nm. A comparison between the two methods is listed in Table 2.6.

Both of the procedures described above involve spectroscopic determination of substances produced during the enzymatic reaction. However, the Xylazyme AX assay is a faster and more cost effective method for rapid screening of multiple numbers of samples because it does not go through a pure xylanase extraction step. The drawback of this procedure is the underestimation of xylanase activity. As the crude extracts are extracted from powdered samples some of the enzymes can get degraded by protease enzymes present in the extract. Another drawback of both assays is they both require construction of standers curves using pure xylanase. In most instances, the standers curves are constructed using xylanases of fungal origin because it is the most commercially available form. Thus, the amount of xylanase present in sample is expressed with respect to a fungal xylanase activity. However, in a screening study both of the 
above drawbacks can be disregarded as the effect is applied on all the samples in a similar way. In both the assays, if we are strictly interested on endogenous xylanase, samples need to be grown in aseptic growth chambers to eliminate the xylanases coming from microbes that can naturally reside on grains.

Table 2.6. Comparison between the Xylazyme AX assay and DNS assay.

\begin{tabular}{ll}
\hline Xylazyme AX assay & DNS assay \\
\hline Substrate for xylanase is Xylazyme AX & Substrate for xylanase is AX \\
Directly measures the amount of soluble & Xylans produced due to xylanase is further \\
Xylazyme AX particles & reacted with DNS to produce colored \\
& compound
\end{tabular}

Measures only the activity of xylanase in the Sample need to be free from other hydrolases presence of other hydrolases

Can be done on crude extract of sample Need to purify the sample before assaying to eliminate other enzymes

Can be used on multiple samples in a short time Pure sample preparation involves multiple frame due to ease of sample preparation cation exchange columns and gel permeation chromatography. Thus cannot be used on many samples in a short time frame.

In a more specific study, dealing with limited number of samples, xylanases can be purified and quantified using classical protein purification techniques utilizing ultrafiltration, 
anion exchange chromatography, and gel filtration techniques (Badal, 2002). Even though this provides more accurate measures of amount of xylanase in a sample, it is time consuming.

\subsubsection{Assay of xylanase inhibitors}

Quantification of xylanase inhibition has been developed by Gebruers et al. (2001) with modifications to the above Xylazyme AX assay procedure. Xylanases of microbial origin are subjected to the inhibition by xylanase inhibitors in wheat extracts over a given period of time. The remaining activity of uninhibited xylanases are determined based on the above describes Xylazyme AX assay procedure. Similarly, the xylanase activity of the microbial xylanases that are not subjected to inhibition is also measured. The amount of inhibited xylanase is calculated by comparing the xylanases activity of inhibited and uninhibited xylanase samples. The estimations are bases on the standers curves platted with purified xylanase inhibitors. However in this quantification procedure, if xylanases of microbial origin are present in the sample, some of the xylanase inhibitors will bind to them and will not be detected in the final assay resulting in underestimation of the actual levels. Thus, the precautions and problems associated with xylanases assay holds true to xylanase inhibition assays, too. Being a rapid and cost effective method, this assay can be used for rapid screening of multiple samples in a short time period. In a more specific context, a combination of extraction and classical protein purification techniques are used to purify and quantify xylanase inhibitors (McLauchlan, 1999; Fierens, 2007b;Debyser et al., 1999; Goesaert et al., 2003a). 


\section{NEED STATEMENT AND OBJECTIVES}

One of the major problems in wheat milling and processing industries is the variability of the end use quality of the wheat (Dornez et al., 2008). Thus, many researches have been done to investigate the effect of growing conditions on starch and protein in grains. The review by Dupont and Altenbach (2003) elaborates on this fact. However, the quality of wheat is not only determined by starch and protein. There are other miner constituents such as lipids, enzymes and non-starch polysaccharides that also affect the wheat quality (Dornez et al., 2008). Of the nonstarch polysaccharides, arabinoxylans are of great importance as they are the most abundant type in the cell wall of wheat (Goesaert et al., 2005). AX have been shown to affect the end use properties of wheat, which is a concern for many wheat based industries including bread making industry, refrigerated dough, animal feed, gluten starch separation, etc. (Courtin and Delcour, 2002; Courtin et al., 2005; Bedford and Schulze, 1998). Endoxylanases are the main enzymes involved in hydrolyzing the AX molecule. They do so by internally hydrolyzing the xylan backbone of the AX molecule. This causes drastic changes to AX molecular weight, water extractability and its functional properties (Courtin and Delcour, 2002). Grain associated endoxylanase in wheat kernels are capable of imparting significant effects on processing (Dornez et al., 2006a; Dornez et al., 2006b). Only limited data is available about the grain associated endoxylanases and to our knowledge no research is done on comparing the North American grown hard red spring wheat and hard white spring wheat endoxylanase levels. Apart from AX and endoxylanase, wheat kernels also contain high levels of endoxylanase inhibitors. These inhibitors inactivate grain associated xylanases from microbial origin and hence affect the net functionality of endoxylanase in wheat processing. Although AX, xylanase and xylanase inhibitors play an important role in wheat processing not much research has been done on the 
contribution of genetic and environmental factors on their variability in wheat kernels. Studies on these areas are important because factors that are under genetic regulation can be manipulated by wheat breeders to develop desired varieties. Moreover, knowledge about the contribution of genotype and environment interaction is also important in deciding the potential of newly developed varieties by breeders.

With this in mind, the main objective of the research was to determine the influence of genotype, growing location and growing location $\mathrm{X}$ genotype interaction on the variability of total AX, xylanase activity, and xylanase inhibition activity in hard red spring wheat and hard white spring wheat. The effect of location and genotype on the substitution pattern of arabinose in $\mathrm{AX}$ was also evaluated. 


\section{MATERIALS AND METHODS}

\subsection{Materials}

All the chemicals and reagents were of analytical grade. All wheat samples were kindly provided by Dr. Mergoum and Mory O.P. Rugg in the Department of Plant Science, North Dakota State University. Twelve genotypes were grown at three locations (Casselton, Carrington, and Prosper, ND) utilizing randomized complete block design with four replicates in 2008. Wheat samples consist of six hard red and six hard white spring wheat genotypes that are adapted to the U.S. Spring Wheat region (Table 4.1). Out of the four replicates, replicate one and two were combined into one, and replicate three and four were combined into one to obtain two replicates. The selected genotypes were selected to represent different origins and planted acres. The $B$. subtilis xylanase and $P$. purpurogenum xylanase were kindly provided by Dr. Kurt Gebruers and Jan Delcour (Leuven Food Science and Nutrition Research Centre, Leuven, Belgium). Xylanase (Xylazyme AX) assay kit (catalogue no: K-XYLS) for the determination of endo-1,4- $\beta$-D-xylanase was purchased from Megazyme (Bray, Ireland). Bovine serum albumin ( $\geq 98 \%$ (agarose gel electrophoresis), lyophilized powder) was purchased from Sigma-Aldrich (Buchs, Switzerland).

\subsection{Sample Preparation}

Hard red spring and hard white spring wheat samples were cleaned by passing through a dockage tester XT5 3/03 (Carter Day International, Minneapolis, MN). Cleaned samples (150 g) were collected on to glass jars and conditioned to $16 \%$ moisture content the day before milling. Next the samples were milled on a Quadramat JR. laboratory mill (C.W. Brabender Instrument, Inc., South Hackensack, NJ) to produce flour and bran. Bran was again ground in cyclone sample mill with a $0.5 \mathrm{~mm}$ screen (UDY Corp, Fort Collins, CO) to reduce particle size. Another 
$50 \mathrm{~g}$ each of cleaned samples were ground in cyclone sample mill with a $0.5 \mathrm{~mm}$ screen (UDY Corp, Fort Collins, CO) to produce whole meal. All samples were stored in sealed plastic bags at $4{ }^{0} \mathrm{C}$ until analysis. Moisture content of all the samples was determined using AACC approved method 44-15A Moisture -Air - Oven Method (AACC International, 1999).

4.3. Determination of Total Arabinoxylans (TOT-AX) and Arabinose to Xylose Ratio (A/X) of Wheat Bran Using Gas Chromatography (GC)

Total arabinoxylans and the ratio between arabinose to xylose in arabinoxylans in wheat bran were determined following acid hydrolysis and preparation of alditol acetates as described by Blakeney et al. (1983). Wheat bran contains the highest amount of AX in the grain, thus, only wheat bran was used in this analysis. Arabinose and xylose were used as monosaccharide standards in the analysis.

\subsubsection{Hydrolysis}

To hydrolyze the polysaccharide to its monomeric constituents (Fox et al., 1989), bran samples (7 mg) were hydrolyzed with Trifluoroacetic acid (TFA) $(2 \mathrm{M}, 250 \mu \mathrm{L})$ for $1 \mathrm{~h}$ at 121 ${ }^{0} \mathrm{C}$. Myo-Inositol ( $75 \mu \mathrm{L}$ of $10 \mathrm{mg} / \mathrm{mL}$ solution) was added to the hydrolyzed samples as an internal standard and dried under nitrogen (Gys et al., 2003). The excess acid was neutralized by adding $\mathrm{NH}_{4} \mathrm{OH}(1 \mathrm{M}, 100 \mu \mathrm{L})$. The resulting mixture contains the hydrolyzed products.

\subsubsection{Reduction}

The hydrolyzed samples were reduced by adding sodium borohydride $\left(\mathrm{NaBH}_{4}\right)$ in a dimethylsulfoxide (DMSO) solution $(20 \mathrm{mg} / \mathrm{mL}, 500 \mu \mathrm{L})$ (Blakeney et al., 1983). In this step, aldose form of the sugars is reduced to an alditol by $\mathrm{NaBH}_{4}$ (Fox et al., 1989). If this reduction is not carried out acetylation of ring form of aldose complicates the chromatogram (in aqueous solution aldoses exist in equilibrium between ring form and open chain but alditols only occur as 
Table 4.1. Genotype, class, origin and pedigree of hard spring wheat samples.

\begin{tabular}{|c|c|c|c|}
\hline Genotype & Class $^{\mathrm{a}}$ & Origin & Pedigree \\
\hline Alsen & HRS & NDSU & ND674//ND2710/ND688,ND2710=ND2603(Sumai3/Wheaton)/ \\
\hline Briggs & HRS & SDSU & AC PASQUA/BERGEN//SD3097 \\
\hline Glenn & HRS & NDSU & ARINA//FO/2791/ND694/3/ND706 \\
\hline Granite & HRS & WPB & ACSS4m-k/3/LNL/TG/312S \\
\hline Hanna & HRS & AgriPro & MN70170/ECM403//KATEPWA/3/BENITO/4/AC DOMAIN \\
\hline Ingot & HRS & SDSU & SD3080/Dalen $($ SD3080 = Butte86 / SD3004) \\
\hline AC Snowbird & HWS & Canada & RL4137*6//TC/POSP48//AC DOMAIN \\
\hline Explorer & HWS & MSU & MT8182/‘Fortuna')//‘Pondera'/MT8182 \\
\hline Lolo & HWS & $\mathrm{U}$ of I & A9158S//‘Oasis 86'/IDO377 \\
\hline CS3100Q & HWS & Canterra & Otane / AC Karma \\
\hline Pristine & HWS & WPB & Fergus/Golden 86' \\
\hline 99S0155-14W & HWS & AgriPro & IVAN/3/HAMER//SUMAI3/DALEN \\
\hline
\end{tabular}

${ }^{\mathrm{a}}$ Wheat class hard red spring is denotes as HRS and hard white spring is denoted as HWS 
open chain). After reduction to alditols, excess $\mathrm{NaBH}_{4}$ was decomposed by the addition of glacial acetic acid (ca. $300 \mu \mathrm{L})$.

\subsubsection{Acetylation}

Alditol acetates were prepared according to the method described by Blakeney et al. (1983) for the preparation of alditol acetates for monosaccharide analysis. 1-methylimidazol (100 $\mu \mathrm{L}$ ) was added as a catalyst for the acetylation reaction (Blakeney et al., 1983;Fox et al., 1989). Acetic anhydride $(500 \mu \mathrm{L})$ was added to the reduced monosaccharaides and the contents were mixed. The reaction was stopped with the addition of $4 \mathrm{~mL}$ of $\mathrm{H}_{2} \mathrm{O}$. The acetylated monosaccharides were extracted twice with methylene chloride. The methylene chloride was evaporated under $\mathrm{N}_{2}$. The residue was redissolved in acetone and transferred to vials for analysis in GC. The derivatized alditol acetate samples were analyzed on a Hewlet Packard 5890 series II GC system with a flame ionization detector (FID) (Agilent Technologies, Inc. Santa Clara, CA). Supelco SP-2380 fused silica capillary column $(30 \mathrm{~m} \times 0.25 \mathrm{~mm} \times 2 \mu \mathrm{m})($ Supelco Bellefonte, PA) was used in the GC system. The system parameters were as follows: flow rate of 0.8 $\mathrm{mL} / \mathrm{min}, 82737 \mathrm{~Pa}$ flow pressure, oven temperature of $100{ }^{0} \mathrm{C}, 250{ }^{0} \mathrm{C}$ of detector temperature, and $230{ }^{\circ} \mathrm{C}$ of injector temperature. The carrier gas was Helium. Arabinoxylans was calculated as the sum of xylose and arabinose monosaccharides.

\subsection{Determination of Arabinose Substitution Pattern Using Proton Nuclear Magnetic Resonance} $\left({ }^{1} \mathrm{H}-\mathrm{NMR}\right)$ Spectroscopy

Arabinose substitution pattern of water-extractable arabinoxylans of wheat bran was determined using proton nuclear magnetic resonance $\left({ }^{1} \mathrm{H}-\mathrm{NMR}\right)$ using the method described by Cleemput et al.(1995). Water extractable AX was extracted from wheat bran samples. Samples of water extractable $\mathrm{AX}(5 \mathrm{mg})$ were dissolved on $700 \mu \mathrm{L}$ of deuterium oxide $\left(\mathrm{D}_{2} \mathrm{O}\right)$, with 
continuous stirring at $40{ }^{0} \mathrm{C}$ for $1 \mathrm{~h}$ and freeze dried. This was repeated for a second time. Then the freeze dried sample was dissolved in $800 \mu \mathrm{L}$ of deuterium oxide $\left(\mathrm{D}_{2} \mathrm{O}\right)$, with continuous stirring at $40{ }^{0} \mathrm{C}$ for $1 \mathrm{~h}$ and transferred to NMR tubes. ${ }^{1} \mathrm{H}-\mathrm{NMR}$ spectra was obtained using a Varian Unity Inova $500 \mathrm{MHz}$ NMR spectrometer (Varian Inc. Palo Alto, CA) at $80{ }^{\circ} \mathrm{C}$.

4.5. Determination of Apparent Xylanase Activity

\subsubsection{Sample preparation}

Whole meal $(2.0 \mathrm{~g})$, flour $(2.0 \mathrm{~g})$ and bran $(1.0 \mathrm{~g})$ were extracted for one hour at $6{ }^{0} \mathrm{C}$ in sodium acetate buffer $\left(25 \mathrm{mM}, \mathrm{pH} 4.7,0.02 \% \mathrm{NaN}_{3}, 20 \mathrm{~mL}\right)$ on a horizontal shaker (150 rpm). The contents were centrifuged $\left(16000 \mathrm{~g}, 4^{0} \mathrm{C}, 15 \mathrm{~min}\right)$ and the supernatants were filtered through VWR Qualitative 413 filter paper (particle retention; 5-13 $\mu \mathrm{m}$ ) to obtain the aqueous extracts which were used in xylanase activity assay.

\subsubsection{Apparent xylanase activity assay}

The Xylazyme AX method (Megazyme, Bray, Ireland) was used with modifications to determine the apparent xylanase activity of whole meal, flour, and bran extracts as described by Gebruers et al (2010). An enzyme standard series (0.295, 0.059, 0.0295, 0.01475 and 0.007375 $\mathrm{mU} / \mathrm{mL})$ in sodium acetate buffer $\left(25 \mathrm{mM}, \mathrm{pH} 4.7,0.02 \% \mathrm{NaN}_{3}\right)$ was prepared using Aspergillus niger xylanase $(295 \mathrm{mU} / \mathrm{mL})$ provided with the Xylazyme AX assay kit. Standards were stored in the refrigerator at $4{ }^{0} \mathrm{C}$ and were not used beyond two days from the date of preparation. Whole meal or flour or bran extracts or buffer (blank) or standard (A. niger xylanase) $(1.000 \mathrm{~mL})$ were drawn to test tubes and equilibrated at $40{ }^{\circ} \mathrm{C}$ for $10 \mathrm{~min}$. The extracts were diluted to obtain a linear relationship between the amount of xylanase present and the activity measured. Then one Xylazyme AX substrate tablet was added to each tube. After the addition of the tablets, the tubes were further incubated for 17 hours at $40{ }^{\circ} \mathrm{C}$. The reaction was stopped by adding Trizma base 
solution $(165 \mathrm{mM}$, pH9.36, $6.00 \mathrm{~mL})$. After $10 \mathrm{~min}$ at room temperature, the solutions were

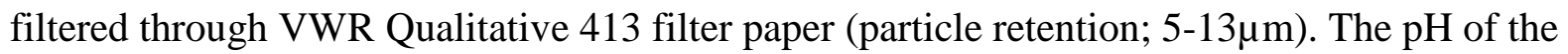
resultant solution was $\mathrm{pH}$ 9.31. Using a spectrophotometer (HACH DR/4000U Spectrophotometer, Hach Company, Loveland, CO) the absorbance was measured at $590 \mathrm{~nm}$ against a blank prepared using sodium acetate buffer. Test tubes provided with the instrument was used in the measurements (diameter, $16 \mathrm{~mm}$ ). Corrections were made for nonenzymic color release by the tablets. Apparent xylanase activity of whole meal, flour and bran was calculated using the standard series of $A$. niger xylanase. Corrections were made for the moisture content of the initial samples and apparent xylanase activity was expressed as milliUnits per gram of dry matter (mU/g of $\mathrm{dm})$ of sample. A schematic representation of the main steps involved in apparent xylanase activity assay is presented in Figure 4.1.

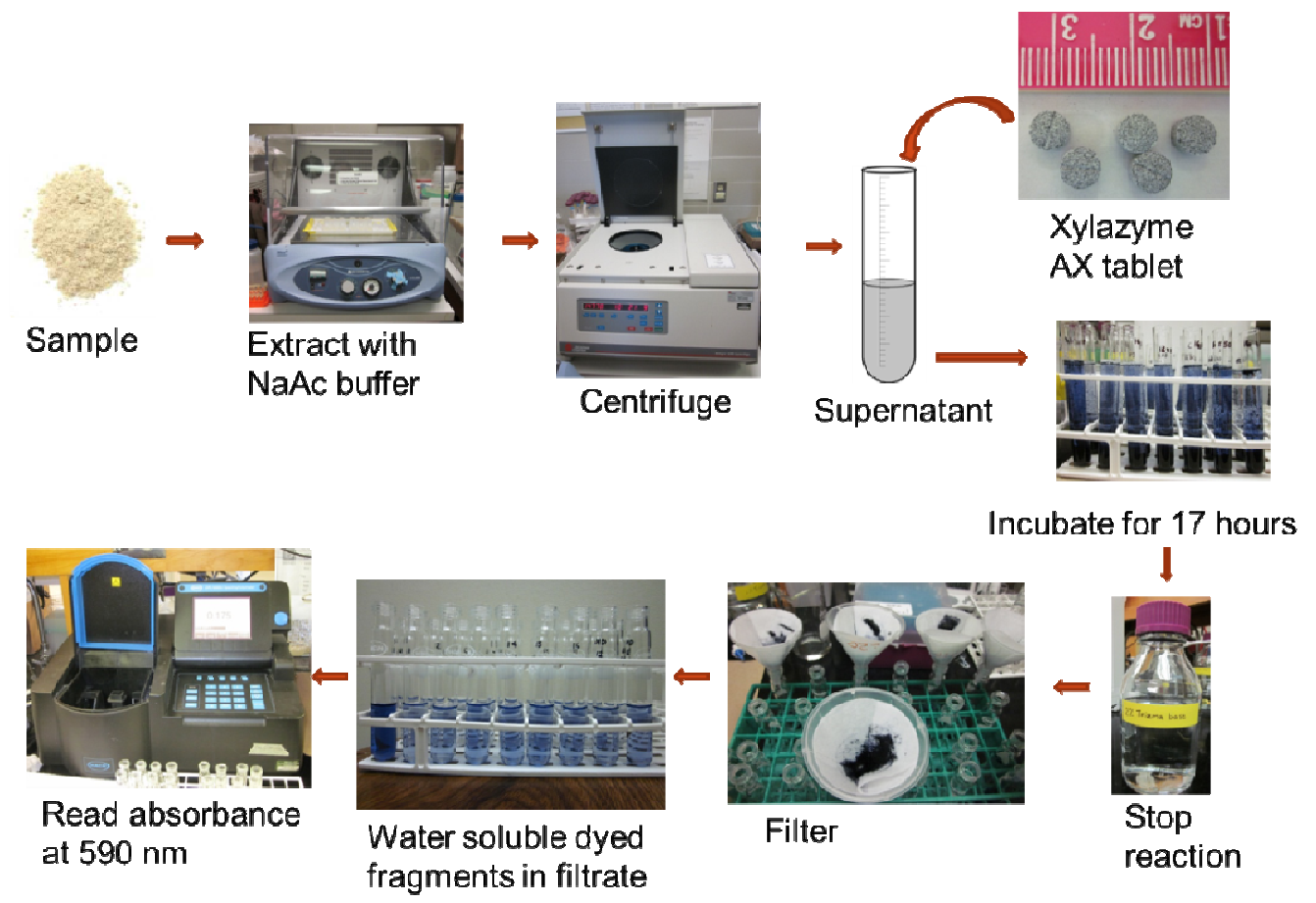

Figure 4.1. Schematic flow diagram illustrating the steps in apparent xylanase activity assay procedure. 


\subsection{Determination of Apparent Xylanase Inhibition Activity of TAXI and XIP}

The levels of TAXI and XIP inhibition were determined using the modified XylazymeAX method described by Dornez et al. (2006b). B. subtilis xylanase was used for TAXI activity and $P$. purpurogenum xylanase for XIP activity, as these xylanases have specific activities towards TAXI and XIP respectively.

\subsubsection{Sample preparation}

Flour $(2.0 \mathrm{~g})$ and bran $(1.0 \mathrm{~g})$ were extracted for one hour at $6{ }^{0} \mathrm{C}$ in sodium acetate buffer (25 mM, pH 4.7, 0.02\% $\mathrm{NaN}_{3}, 20 \mathrm{~mL}$ ) on a horizontal shaker (150 rpm). The contents were centrifuged (16000g, $4{ }^{0} \mathrm{C}, 15 \mathrm{~min}$ ) and the supernatants were filtered through VWR Qualitative 413 filter paper (particle retention; $5-13 \mu \mathrm{m}$ ) to obtain the aqueous extracts which were used in xylanase inhibition activity assays.

\subsubsection{Apparent xylanase inhibition activity assay}

TAXI and XIP activities were measured using the modified Xylazyme AX assay procedure as described by Dornez et al. (2006b). B. subtilis xylanase and P. purpurogenum xylanase enzyme solutions were prepared in sodium acetate buffer $(25 \mathrm{mM}, \mathrm{pH} 4.7,0.02 \%$ $\left.\mathrm{NaN}_{3}\right)$ containing BSA $(0.5 \mathrm{~g} / \mathrm{L})$. Each xylanase enzyme solution was diluted to obtain an absorbance within the range of 0.200 to 0.900 when used in the assay without the inhibitor. These xylanase enzyme solutions $(0.5 \mathrm{~mL})$ of $B$. subtilis xylanase or $P$. purpurogenum xylanase were pre-incubated at $30{ }^{\circ} \mathrm{C}$ for 30 min with an equal volume of sodium acetate buffer (uninhibited reference, UR) or wheat extract (inhibited sample, IS). After pre-incubation, Xylazyme AX substrate tablets were added to each tube and incubated at $30{ }^{0} \mathrm{C}$ for $1 \mathrm{hr}$. Then Trizma base $(165 \mathrm{mM}, \mathrm{pH} 9.36,6.00 \mathrm{ml})$ was added and vortexed to stop the reaction and let stand for $10 \mathrm{~min}$ at room temperature. Then the contents were filtered through filter paper 
(VWR 413). Absorbance of the samples and the reference were measured using a spectrophotometer (HACH DR/4000U Spectrophotometer, Hach Company, Loveland, CO), at $590 \mathrm{~nm}$. Absorbance of the uninhibited reference (UR) was measured against the control for uninhibited reference (C-UR) prepared using sodium acetate buffer instead of xylanase enzyme. Absorbance of the each inhibited sample (IS) was measured against corresponding control for inhibited sample (C-IS) prepared using wheat extract in buffer instead of xylanase enzyme solution. Test tubes provided with the instrument was used in the measurements (diameter, $16 \mathrm{~mm})$. A schematic flow chart of the assay procedure is given in Figure 4.2. Xylanase inhibition activity was expressed in inhibition units (InU) as defined by Gebruers et al.(2010) where $1 \mathrm{InU}$ is the amount of xylanase inhibitor needed to inhibit xylanase activity by $50 \%$ in the above described assay. The use of units for the quantification of xylanase inhibitors was due to the unavailability of the pure inhibitors, TAXI or XIP to construct a dose response curve. The calculation of inhibition units in each sample is given in the following calculation.

Absorbance of UR (against C-UR) $\quad=\mathrm{A}_{1}$

Absorbance of IS (against C-IS) $\quad=\mathrm{A}_{2}$

Inhibited xylanase activity $\% \quad \frac{\left(\mathrm{A}_{1}-\mathrm{A}_{2}\right)}{\mathrm{A}_{1}} \times 100=\mathrm{P} \%$

According to the definition of inhibition units (InU);

Amount of xylanase inhibitor needed to inhibit $50 \%$ of xylanase activity $=1 \mathrm{InU}$

Amount of xylanase inhibitor needed to inhibit $\mathrm{P} \%$ of xylanase activity $=\frac{1 \mathrm{InU} \times \mathrm{P}}{50}=\mathrm{Y} \operatorname{InU}$

Amount of xylanase inhibition units in $\mathrm{X}$ mL of sample $=\underline{\mathrm{Y} \times \mathrm{X} \operatorname{InU}}$ 




Figure 4.2. Schematic flow diagram illustrating the steps in apparent xylanase inhibition assay procedure. B. subtilis xylanase (BSX); P. purpurogenum xylanase (PPX); uninhibited reference (UR); inhibited sample (IS); control for uninhibited reference (C-UR); control for inhibited sample (C-IS). 


\section{RESULTS AND DISCUSSION}

Arabinoxylans (AX), xylanase, and xylanase inhibitors have significant impact on processing conditions of cereals. The distinct physicochemical characteristics of both waterextractable (WE-AX) and water-unextractable (WU-AX) AX affect grain functionality in food processes even though AX are only relatively minor components of grain. Endo- $\beta-(1,4)-\mathrm{D}-$ xylanases (EC 3.2.1.8, xylanases), are the most significant AX hydrolyzing enzymes, which degrade internal $\beta$-(1,4)-linkages between xylose residues in the xylan backbone. Therefore, they can considerably affect molecular mass (MM) and water holding capacity of AX, and thus also their functions during cereal processing. In this study, the effect of genotype, growing location, and their interactions on apparent xylanase and apparent xylanase inhibition activities of Triticum aestivum xylanase inhibitor (TAXI) and xylanases inhibiting protein (XIP) of wheat was studied using six hard red spring wheat and six hard white spring wheat genotypes, which were grown in Carrington, Prosper and Casselton, ND in 2008. Previous studies showed significant environmental effect for apparent xylanase activity in grain (Simsek and Ohm, 2009), thus, weather conditions will be briefly discussed.

\subsection{Environmental Conditions}

Environmental conditions with respect to temperature and rain fall in 2008 growing season are given in table 5.1. Each location received lower than average precipitation in the early part of the growing season. Temperatures were below normal at both environments in the early part of the growing season. Prosper had a higher precipitation and a higher temperature compared to Carrington, which can result in higher disease pressure in Prosper than in Carrington. 
Table 5.1. Precipitation and temperature for the growing season at Carrington, and Prosper, North Dakota in 2008.

\begin{tabular}{|c|c|c|c|c|c|c|c|}
\hline \multirow[b]{2}{*}{ Environment } & \multicolumn{3}{|c|}{ Precipitation (mm) } & \multicolumn{4}{|c|}{ Temperature $\left({ }^{\circ} \mathrm{C}\right)$} \\
\hline & Month & Total & $\%$ Normal $\dagger$ & Max. & Min. & Avg. & \pm Normal $\dagger$ \\
\hline \multirow[t]{4}{*}{ Carrington } & May & 30 & 48 & 18 & 2 & 10 & -4 \\
\hline & June & 127 & 132 & 22 & 10 & 16 & -2 \\
\hline & July & 47 & 59 & 27 & 14 & 20 & 0 \\
\hline & Aug. & 39 & 62 & 27 & 12 & 20 & -1 \\
\hline \multirow[t]{4}{*}{ Prosper } & May & 38 & 57 & 20 & 4 & 12 & -1 \\
\hline & June & 164 & 180 & 23 & 11 & 17 & -1 \\
\hline & July & 75 & 91 & 27 & 14 & 20 & 0 \\
\hline & Aug. & 77 & 113 & 28 & 13 & 20 & 0 \\
\hline
\end{tabular}

$\dagger$ Based on 1971-2007 average.

$\ddagger$ Due to the proximity of the location, data used for Casselton

(Table adapted from Rugg (2011))

5.2. Total Arabinoxylans (TOT-AX) and Arabinose to Xylose Ratio (A/X) of Wheat Bran AX play an important role in wheat based products through their high water absorbing capacity and ability to form hydrated networks via chain entanglement or covalent bonding via ferulic acid residues in neighboring AX chains (Izydorczyk and Biliaderis, 1992). Thus, evaluating the factors that can affect the structure and quantity of AX is important. The TOT-AX (\%) and $\mathrm{A} / \mathrm{X}$ ratio of 12 hard spring wheat genotypes harvested in 2008 are given in Table 5.2. TOT-AX in bran varied from $14.99 \%$ in Lolo to $27.96 \%$ in Explorer among genotypes. These 
values were in agreement with the values reported in literature. Gebruers et al.(2010) reported a range of 12.1 to $19.2 \%$ TOT-AX in bran, using 20 spring wheat genotypes grown in Europe. Combined analysis of variance for the 12 genotypes across three locations for TOT-AX gave no significant difference $(\mathrm{P}<0.05)$ between genotypes (Table 5.2). Dornez et al. (2008) analyzed six wheat varieties grown in Europe and found that only $18 \%$ of the total variation in AX in their wheat samples could be explained by genotype. Also, Andersson et al. (1993) reported that no relation could be found between the non-starch polysaccharides level and genotype in wheat grain. Thus, results in the current research are in agreement with other findings.

The substitution pattern of AX is an important factor in AX since it influences the shape, solubility, and molecular characteristics of the AX polymer (Storsley et al., 2003). In general, the presence of substitution in polymers limits their chain-chain interactions which make the polymer more water soluble. However, in the case of AX, water solubility is not only governed by presence of substitution, but also by the covalent linkage to other cell wall components and other chains (Saulnier et al., 2007). For example, water extractable AX (WE-AX) have a lower $\mathrm{A} / \mathrm{X}$ ratio than water un-extractable $\mathrm{AX}$ (WU-AX). But the high level of diferulic covalent linkage among AX chains in WU-AX makes them water insoluble. All of the genotypes we studied had high $\mathrm{A} / \mathrm{X}$ ratios indicating high level of arabinose substitution in AX. We also observed significant differences in $\mathrm{A} / \mathrm{X}$ ratio among genotypes $(\mathrm{P}<0.05)$ (Table 5.2). This indicates that variation in substitution pattern in $\mathrm{AX}$ is dependent on genotype. This was in agreement with observations of other researchers who also found significant variation in AX substitution among varieties (Storsley et al., 2003; Simsek and Ohm, 2009). 
Table 5.2. Average total arabinoxylans (TOT-AX) and arabinose to xylose (A/X) ratio of wheat bran of 12 hard spring wheat genotypes grown at three locations, Carrington, Casselton, and Prosper, ND in 2008.

\begin{tabular}{|c|c|c|}
\hline Genotype & TOT-AX (\% of d.m.) & $\mathrm{A} / \mathrm{X}$ ratio \\
\hline Alsen $^{a}$ & 18.97 & 0.91 \\
\hline Briggs $^{a}$ & 21.65 & 0.89 \\
\hline Glenn $^{\mathrm{a}}$ & 18.87 & 0.98 \\
\hline Granite $^{\mathrm{a}}$ & 18.21 & 0.95 \\
\hline Hanna $^{\mathrm{a}}$ & 20.92 & 0.91 \\
\hline Ingot $^{\mathrm{a}}$ & 23.24 & 0.89 \\
\hline AC Snowbird $^{\mathrm{b}}$ & 20.14 & 0.91 \\
\hline Explorer ${ }^{b}$ & 27.69 & 0.93 \\
\hline Lolo $^{b}$ & 14.99 & 0.92 \\
\hline $\mathrm{CS} 3100 \mathrm{Q}^{\mathrm{b}}$ & 20.29 & 0.93 \\
\hline Pristine $^{\mathrm{b}}$ & 21.25 & 0.95 \\
\hline $99 \mathrm{~S} 0155-14 \mathrm{~W}^{\mathrm{b}}$ & 25.58 & 0.82 \\
\hline $\operatorname{LSD}(5 \%)^{\mathrm{c}}$ & ns & 0.05 \\
\hline \multicolumn{3}{|c|}{${ }^{\mathrm{a}}$ Hard red spring wheat } \\
\hline${ }^{\mathrm{b}}$ Hard white spri & & \\
\hline
\end{tabular}


Table 5.3. Combined Analysis of Variance (genotype fixed; location random) for TOT-AX (\% d.m.) and $\mathrm{A} / \mathrm{X}$ ratio.

\begin{tabular}{|c|c|c|c|c|}
\hline \multirow{3}{*}{$\begin{array}{l}\text { Source } \\
\text { Location (L) }\end{array}$} & \multicolumn{4}{|c|}{ F-value } \\
\hline & \multicolumn{2}{|c|}{ TOT-AX (\% of d.m.) } & \multicolumn{2}{|l|}{$\mathrm{A} / \mathrm{X}$ ratio } \\
\hline & 0.56 & ns & 3.79 & $\mathrm{~ns}$ \\
\hline Rep(Location) & 1.18 & ns & 0.81 & $\mathrm{~ns}$ \\
\hline Genotype (G) & 1.93 & ns & 3.92 & $* *$ \\
\hline $\mathrm{L}^{*} \mathrm{G}$ & 12.96 & $* * *$ & 1.41 & $\mathrm{~ns}$ \\
\hline Red (R) vs White (W) & 12.03 & $* *$ & 2.05 & ns \\
\hline R vs W- Carrington & 25.71 & $* * *$ & 2.04 & ns \\
\hline R vs W- Casselton & 4.7 & $*$ & 0.81 & ns \\
\hline R vs W- Prosper & 1.15 & ns & 1.17 & ns \\
\hline
\end{tabular}

*** $P$-value $<0.001 ; * * P$-value $<0.01 ; * P$-value $<0.05$; ns non-significant

Table 5.3 gives the F-values corresponding to each source of variation for TOT-AX and $\mathrm{A} / \mathrm{X}$ ratio. Thus, the TOT-AX in the samples being tested are dependent on location $(\mathrm{L})$ by Genotype $(\mathrm{G})$ interaction $\left(\mathrm{L}^{*} \mathrm{G}\right)$. Even though there was no significant difference between genotypes as a whole, there was a significant difference between HRSW and HWSP genotype means of TOT-AX ( $P$-value $<0.01)$. However, no such significant difference was observed for $\mathrm{A} / \mathrm{X}$ ratio between the wheat classes HRSW and HWSW.

\subsection{Substitution Pattern of AX Using ${ }^{1} \mathrm{H}-\mathrm{NMR}$}

WE-AX was extracted from bran samples belonging to four genotypes from all three locations and was analyzed using ${ }^{1} \mathrm{H}-\mathrm{NMR}$ spectroscopy. The representative ${ }^{1} \mathrm{H}-\mathrm{NMR}$ spectrum is given in Figure 5.1. with its resonances assignments. The spectrum consists of two distinct 
groups of signals. The anomeric protons of $\alpha$-L-arabinofuranosyl ( $\alpha$-Araf) account for the resonances occurring at the range of $\delta 4.4$ to $4.7 \mathrm{ppm}$ (Hoffmann et al., 1992). The signals at the region $\delta 5.2$ to $5.4 \mathrm{ppm}$ have been attributed to the anomeric protons of $\beta$-D-xylopyranosyl residues $(\beta$-Xyl $p)$ (Figure 5.1). The anomeric proton of arabinose residue linked to the monosubstituted xylose at O-3 position corresponds to the resonance at $\delta 5.4 \mathrm{ppm}$ (signal 1). The signals at $\delta 5.3 \mathrm{ppm}$ corresponds to anomeric proton of arabinose residue linked to the disubstituted xylose at O-3 position (signal 2) and $\delta 5.22 \mathrm{ppm}$ peak is for anomeric proton of arabinose residue linked to the di-substituted xylose at $\mathrm{O}-2$ position (signal 4). The anomeric proton of arabinose residue linked to the di-substituted xylose at O-2 position, when the xylose has an adjoining di-substituted xylose residue gives rise to the resonance (signal 3) between signal two and four at $\delta 5.26 \mathrm{ppm}$. The anomeric proton of di-substituted, mono-substituted and non-substituted xylose residues corresponds to signals 5, 6, and 7 respectively. From the ${ }^{1} \mathrm{H}$ NMR spectra, the peak proportions of signals 1-4 were calculated (Table 5.4). From the two HRSW genotypes, Ingot had a tendency of having high proportions of di-substituted xylose with neighboring di-substituted xylose $\left(\mathrm{X}_{3}\right)$ in all three locations. Also the mono-substituted xylose in Ingot was relatively low. Similar trend was observed for the HWSW genotype, Lolo. This indicated that AX in Ingot and Lolo are highly substituted. Differences in the proportion of substitution were seen between genotypes. But the variation was not constant across all three locations. It has been suggested that the distribution of arabinose along the xylose backbone is irregular (Dervilly-Pinel et al., 2004). Random distribution of clusters with high substitution patterns and low substitution patterns have been identified in AX in wheat (Dervilly-Pinel et al., 2004; Gruppen et al., 1993). This might help explain the non-consistent variation in each substitution proportion seen across genotypes and across locations. However, the distribution of 
the type of substitution (mono- or di-substitution) is considered as a non-random process (Dervilly-Pinel et al., 2004; Gruppen et al., 1993). The biosynthetic mechanism for AX indicates a preference for di-substitution. This trend can be observed in our data too. The mono-substituted xylose proportion is the smallest proportion in all the genotypes at all locations being tested.

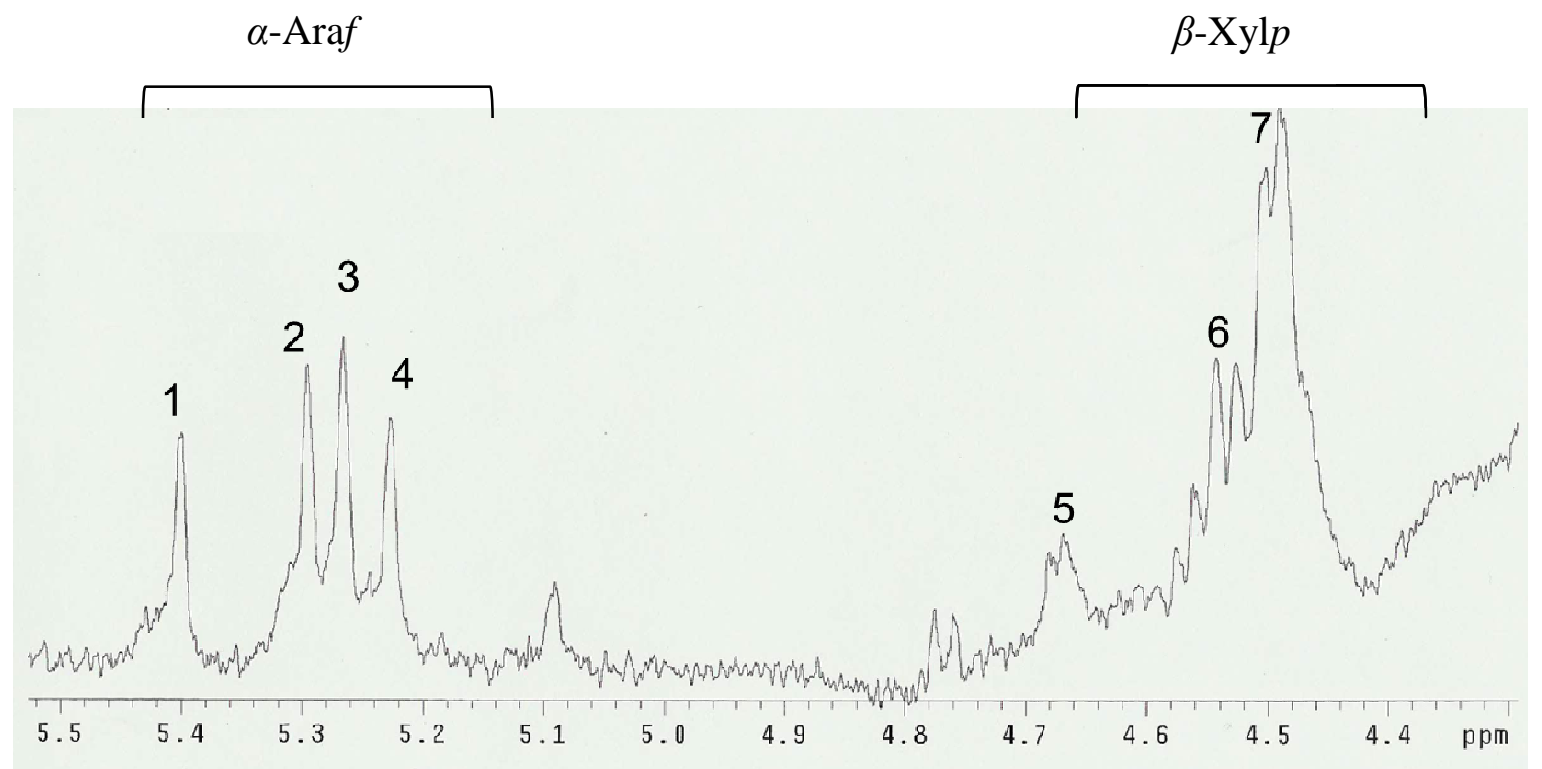

Figure 5.1. Proton nuclear magnetic resonance spectrum of the WE-AX of wheat bran. The numbers assigned for the signals represents the following substitution:

1- $\mathrm{X}_{1}$ - anomeric proton of arabinose residue linked to the mono-substituted xylose at O-3 position

2- $\mathrm{X}_{2}$ - anomeric proton of arabinose residue linked to the di-substituted xylose at O-3 position 3- $\mathrm{X}_{3}$ - anomeric proton of arabinose residue linked to the di-substituted xylose at O-2 position, while the xylose has an adjoining di-substituted xylose residue

4- $\mathrm{X}_{4}$ - anomeric proton of arabinose residue linked to the di-substituted xylose at O-2 position 5-Anomeric proton of di-substituted xylose residue

6- Anomeric proton of mono-substituted xylose residue

7-Anomeric proton of non-substituted xylose residue (Resonance assignments were based on Hoffmann et al. (1992)) 
Table 5.4. Proportions (\%) of mono-, di-, and neighboring di- substituted xylose in water extractable arabinoxylans calculated using ${ }^{1} \mathrm{H}$ - NMR spectral data for four hard spring wheat genotypes grown in Prosper, Casselton and Carrington, ND in 2008.

\begin{tabular}{|c|c|c|c|c|c|}
\hline \multirow[t]{2}{*}{ Genotype } & \multirow[t]{2}{*}{ Location } & \multicolumn{4}{|c|}{ Proportion $(\%)^{\mathrm{ab}}$} \\
\hline & & $\mathrm{X}_{1}$ & $\mathrm{X}_{2}$ & $\mathrm{X}_{3}$ & $\mathrm{X}_{4}$ \\
\hline \multirow[t]{3}{*}{ Granite $^{c}$} & Prosper & 24.93 & 31.01 & 24.88 & 19.19 \\
\hline & Casselton & 15.07 & 30.84 & 33.63 & 20.47 \\
\hline & Carrington & 21.75 & 30.93 & 27.06 & 20.26 \\
\hline \multirow[t]{3}{*}{ Ingot $^{c}$} & Prosper & 14.44 & 27.73 & 36.26 & 21.57 \\
\hline & Casselton & 12.25 & 27.03 & 39.26 & 21.48 \\
\hline & Carrington & 14.80 & 30.56 & 32.44 & 22.21 \\
\hline \multirow[t]{3}{*}{ Lolo $^{d}$} & Prosper & 14.48 & 28.99 & 35.60 & 20.95 \\
\hline & Casselton & 19.77 & 23.26 & 36.04 & 20.94 \\
\hline & Carrington & 14.48 & 28.07 & 31.57 & 14.61 \\
\hline \multirow[t]{3}{*}{$99 S 0155-14 w^{d}$} & Prosper & 9.90 & 36.69 & 34.29 & 19.13 \\
\hline & Casselton & 18.26 & 28.12 & 31.18 & 22.45 \\
\hline & Carrington & 24.07 & 28.42 & 28.13 & 19.40 \\
\hline \multicolumn{6}{|c|}{$\mathrm{X}_{1}-\mathrm{Xylose}$ with mono-substitution (arabinose at O-3) } \\
\hline \multicolumn{6}{|c|}{$\mathrm{X}_{2}-\mathrm{Xylose}$ with di-substitution (arabinose at O-3) } \\
\hline \multicolumn{6}{|c|}{$\mathrm{X}_{3}-$ Xylose with di-substitution (arabinose at O-2) with neighboring di-substituted xylose } \\
\hline \multicolumn{6}{|c|}{$\mathrm{X}_{4}-$ Xylose with di-substitution (arabinose at O-2) } \\
\hline \multicolumn{6}{|c|}{${ }^{\text {a }}$ Results calculated from the peak proportions of the respective anomeric proton of the ${ }^{1} \mathrm{H}-\mathrm{NMR}$} \\
\hline \multicolumn{6}{|c|}{${ }^{\mathrm{b}}$ Data are mean values of duplicate analysis } \\
\hline \multicolumn{6}{|c|}{${ }^{\mathrm{c}}$ Hard red spring wheat } \\
\hline${ }^{\mathrm{d}}$ Hard white spri & heat & & & & \\
\hline
\end{tabular}




\subsection{Apparent Xylanase Activity}

Based on previous published data (Dornez et al., 2006b), apparent xylanase levels (here after referred to as xylanase activity) can vary to a large extent. Also, this variation is largely dependent on genotype and environment. Table 5.5 lists the apparent xylanase activity level in wheat bran, flour, and whole meal in twelve different genotypes (six HRSW and six HWSW) grown in three locations in 2008. In bran, apparent xylanase activity level varied from 0.77 to $60.09 \mathrm{mU} / \mathrm{g}$ d.m. In flour, the variation was from 0.001 to $7.97 \mathrm{mU} / \mathrm{g}$ d.m. Gebruers et al. (2010) found similar results for wheat flour and wheat bran xylanase activity. The whole meal had a xylanase activity which ranged between the bran and flour range, varying from 0.12 to 30.99 mU/g d.m. Similar ranges were seen for whole meal xylanase activity by Dornez et al. (2008). Thus, xylanase activity is mainly concentrated in the wheat bran while wheat flour contains low levels of xylanase. This general trend was seen by other researchers (Dornez et al., 2006c; Gebruers et al., 2010; Gys et al., 2004) who attributed most of the xylanase activity in grain to be a result of microbes residing mostly on the outer layers of the grain. However, it is routine to add external xylanase to wheat flour to facilitate AX degradation. Studies have shown that debranning of wheat kernels prior to milling helps reduce xylanase activity in wheat flour (Gys et al., 2004). As xylanase play an important role in industries that use wheat, reduction of xylanase levels can have a positive or negative effect, depending on its intended end use. For example it is generally considered that microbial xylanase have a preference for WE-AX (Gys et al., 2004). But WE-AX are desirable in wheat flour bread making as they help stabilize gas cells in the dough, resulting in higher loaf volume (Courtin and Delcour, 2002).Thus, debranning has a positive effect on bread. However, it will also reduce the level of xylanase with preference for 
WU-AX too. This will be a negative effect as hydrolysis of WU-AX is preferred in bread making as WU-AX destabilize the gas cells in the dough (Courtin and Delcour, 2002; Gys et al., 2004). Preharvest sprouting in grain can lead to increased levels of xylanase in grain (Dornez et al., 2008). As the kernel starts to germinate more endogenous xylanase is produced in the kernel to degrade the cell walls and make the starch and protein more accessible to amylolytic enzymes. However, based on the alpha amylase activity data for our samples, none of the samples seemed to have preharvest sprouting (Lu, 2011). However, the temperature and precipitation was relatively higher in Prosper compared to Carrington during the growing season of 2008. This could have led to an increased microbial population in the Prosper samples. In our study, the xylanase activity level in bran, flour and whole meal was highest in Prosper, followed by Casselton and Carrington (Table 5.5). We conducted the Bartlett's test to find the homogeneity of variance between locations (Table A.1.). There were significant differences between variances for flour, and whole meal xylanase activity levels. When the xylanase activity levels for whole meal was log transformed, Bartlett's test for homogeneity of variance was non-significant. Therefore, log transformed values of xylanase activity levels for whole meal were used in combined analysis of variance (ANOVA). The ANOVA table for bran and whole meal (Log transformation) xylanase activity is given in Table 5.6. According to that, there is a significant difference among the locations, genotypes and location by genotype interaction for xylanase activity levels for bran and whole meal. Also, there is a significant difference between the HRSW and HWSW genotypes. The location mean xylanase activity in each genotype is presented in Table A.2. From the HRSW genotypes, Ingot had the lowest xylanase activity (3.0 $\mathrm{mU} / \mathrm{g}$ d.m.), while Granite had the highest xylanase activity of 37.3 in bran. In the case of 
Table 5.5. Apparent xylanase activity in bran, flour and whole meal for 12 hard spring wheat genotypes grown at three different locations, Carrington, Casselton, and Prosper, ND in 2008.

\begin{tabular}{|c|c|c|c|c|c|c|c|c|c|}
\hline \multirow[t]{3}{*}{ Genotype } & \multicolumn{9}{|c|}{ Apparent xylanase activity ${ }^{\mathrm{a}}(\mathrm{mU} / \mathrm{g}$ d.m.) } \\
\hline & \multicolumn{3}{|c|}{ Bran } & \multicolumn{3}{|c|}{ Flour } & \multicolumn{3}{|c|}{ Whole meal } \\
\hline & Carrington & Casselton & Prosper & Carrington & Casselton & Prosper & Carrington & Casselton & Prosper \\
\hline Alsen $^{b}$ & 2.69 & 14.93 & 18.08 & 0.02 & 0.19 & 0.38 & 0.38 & 3.25 & 6.17 \\
\hline Briggs $^{b}$ & 1.77 & 6.03 & 16.67 & 0.02 & 0.12 & 0.65 & 0.12 & 1.06 & 6.86 \\
\hline Glenn $^{\mathrm{b}}$ & 0.95 & 12.89 & 16.00 & 0.00 & 0.05 & 0.31 & 0.89 & 2.19 & 4.59 \\
\hline Granite $^{\mathrm{b}}$ & 2.31 & 49.45 & 60.09 & 0.67 & 3.33 & 4.10 & 4.18 & 22.68 & 28.13 \\
\hline Hanna $^{\mathrm{b}}$ & 6.18 & 10.31 & 20.07 & 1.01 & 0.50 & 0.77 & 4.62 & 5.29 & 9.51 \\
\hline Ingot $^{\mathrm{b}}$ & 1.36 & 2.30 & 5.37 & 0.01 & 0.26 & 0.52 & 0.72 & 2.08 & 4.66 \\
\hline AC Snowbird $^{\mathrm{c}}$ & 7.26 & 10.51 & 29.79 & 2.08 & 1.27 & 2.80 & 7.47 & 8.23 & 15.43 \\
\hline Explorer $^{\mathrm{c}}$ & 4.71 & 27.02 & 37.88 & 0.34 & 2.06 & 3.87 & 3.60 & 16.02 & 25.32 \\
\hline Lolo $^{c}$ & 5.47 & 58.40 & 57.33 & 1.11 & 7.97 & 7.05 & 3.62 & 31.78 & 30.99 \\
\hline $\mathrm{CS} 3100 \mathrm{Q}^{\mathrm{c}}$ & 9.72 & 33.97 & 46.63 & 3.05 & 2.70 & 3.34 & 6.43 & 7.46 & 28.30 \\
\hline Pristine $^{c}$ & 0.77 & 46.92 & 44.97 & 0.94 & 3.78 & 3.70 & 4.58 & 22.77 & 26.10 \\
\hline $99 \mathrm{~S} 0155-14 \mathrm{~W}^{\mathrm{c}}$ & 2.52 & 8.39 & 14.36 & 0.01 & 0.46 & 0.79 & 0.49 & 3.24 & 5.82 \\
\hline $\operatorname{LSD}^{\mathrm{d}}(5 \%)$ & 6.20 & 6.20 & 6.20 & ns & 1.28 & 0.96 & 0.70 & 0.70 & 0.70 \\
\hline
\end{tabular}

\footnotetext{
${ }^{a}$ Data are mean values of duplicate analysis

${ }^{\mathrm{b}}$ Hard red spring wheat

${ }^{\mathrm{c}}$ Hard white spring wheat

${ }^{\mathrm{d}}$ LSD, least significant difference; ns, non-significant
} 
HWSW genotypes, the experimental line 99SO155-14w had the lowest xylanase activity of 8.4 mU/g d.m., while Lolo had the highest xylanase activity of $40.4 \mathrm{mU} / \mathrm{g}$ d.m. in bran.

Table 5.6. Combined Analysis of Variance (genotype fixed; location random) of bran and whole meal xylanase activity.

\begin{tabular}{|c|c|c|c|c|}
\hline \multirow{3}{*}{$\begin{array}{l}\text { Source } \\
\text { Location (L) }\end{array}$} & \multicolumn{4}{|c|}{ F Value } \\
\hline & \multicolumn{2}{|l|}{ Bran } & \multicolumn{2}{|c|}{ Whole meal (Log transformation) } \\
\hline & 20.0 & $* * *$ & 42.3 & $* * *$ \\
\hline $\operatorname{Rep}($ Location) & 1.1 & ns & 0.81 & ns \\
\hline Genotype (G) & 4.7 & $* *$ & 9.87 & $* * *$ \\
\hline $\mathrm{L}^{*} \mathrm{G}$ & 22.3 & $* * *$ & 3.9 & $* * *$ \\
\hline Red (R) vs White (W) & 252.2 & $* * *$ & 142.26 & $* * *$ \\
\hline R vs W- Carrington & 13.2 & $* * *$ & 72.35 & $* * *$ \\
\hline $\mathrm{R}$ vs W-Casselton & 139.4 & $* * *$ & 60.31 & $* * *$ \\
\hline R vs W- Prosper & 156.0 & $* * *$ & 41.2 & $* * *$ \\
\hline
\end{tabular}

*** $P$-value $<0.0001 ; * * P$-value $<0.001 ; * P$-value $<0.05$; ns non-significant

Contribution from each variable to xylanase activity in bran and whole meal was evaluated using statistical methods. SAS (Window Version 6.1) 'MIXED' procedure was used to calculate the variance components (Figure 5.2.). About half of the variability in xylanase activity in bran and whole meal can be attributed to the effect of the location. This was similar to the findings by others (Gebruers et al., 2010), who found 51\% contribution from environment to xylanase activity in bran. Approximately $30 \%$ of the variation can be related to genotype and $25 \%$ variation comes from $\mathrm{L}^{*} \mathrm{G}$ interaction. The relative high level of $\mathrm{L} * \mathrm{G}$ interaction term indicate that bran xylanase level is not a very stable breeding parameter. However, Ingot and the 
experimental line 99S0155-14W have a tendency towards low xylanase activity while Granite and Lolo have a tendency towards high xylanase activity in all the three locations. Thus, these genotypes can be suitable candidates for further research.

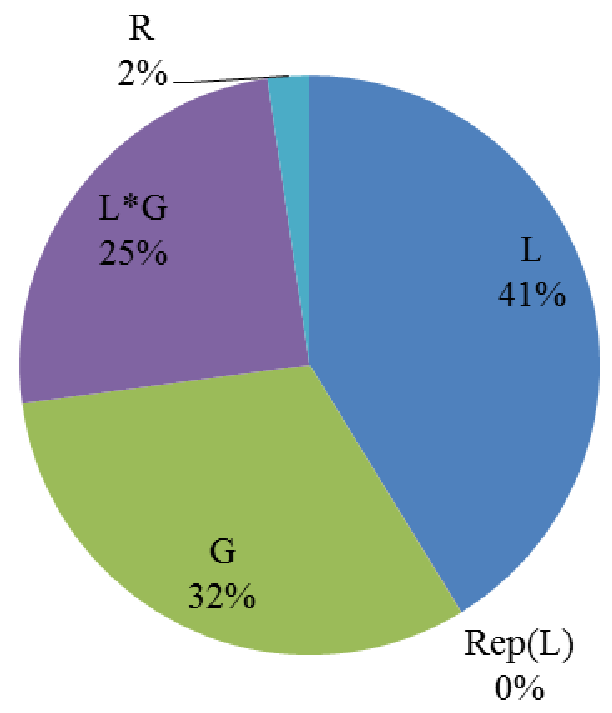

a

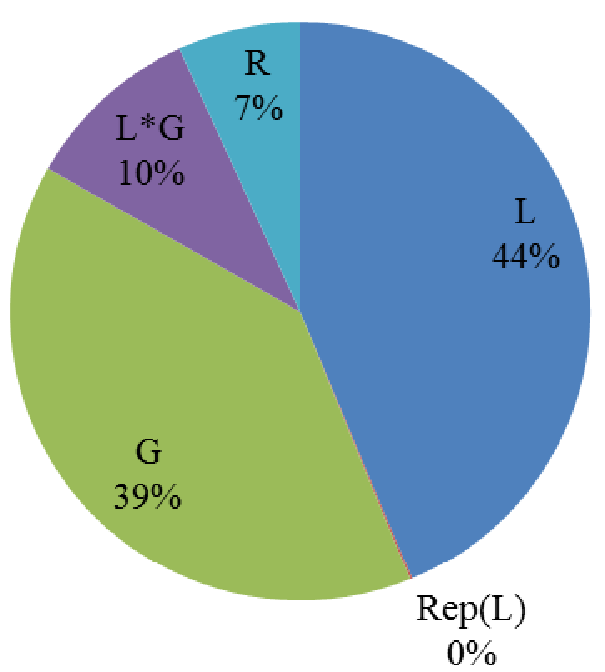

b

Figure 5.2. Contribution (\%) of genotype $(\mathrm{G})$, location (L), interaction between $\mathrm{L}$ and $\mathrm{G}(\mathrm{L} * \mathrm{G})$, replicates by $L(\operatorname{Rep}(\mathrm{L}))$ and the residual variability that cannot be explained by above variables (R) to the apparent xylanase activity of wheat bran (a) and whole meal (b).

\subsection{Apparent Xylanase Inhibition Activity of TAXI and XIP}

The TAXI and XIP inhibition activity levels in bran and flour resulted from different locations are given in Figure 5.3 and Figure 5.4 respectively. On average, highest level of TAXI in the bran was seen in Alsen while the lowest was for Granite. However, this was not the case in flour TAXI levels. Granite had the lowest levels of TAXI in flour but Alsen also had considerably low levels of TAXI in flour. The average bran TAXI activity levels varied from 232.3 to 1007.0 InU/g of d. m. For flour, TAXI activity varied from 11.95 to $274.13 \mathrm{InU} / \mathrm{g}$ of d. m. Thus, bran contained higher levels of TAXI than did flour (ca. 5 fold increase). Other studies has also shown 
higher levels of TAXI in bran than in flour (Gebruers et al., 2010).The combined analysis of variance was conducted for bran TAXI, XIP and flour XIP (Table 5.7). Combine analysis of variance on flour TAXI could not be performed as the variance for flour TAXI across the three locations were significantly different according to Bartlett's test for homogeneity of variance (Table A.1) Analysis of variance showed that bran TAXI levels had significant differences between genotypes at 5\% level of significance (Figure 5.3). However, they showed no significant difference between locations at 5\% level of significance. Thus, TAXI activity in wheat bran is mainly dependent on genotype. On the other hand, there was no significant difference between bran TAXI activity in the two classes of HRSW and HWSW at 5\% level of significance.

In the case of XIP, on average highest bran XIP levels were seen in Ingot while lowest XIP levels were seen in Granite (Figure 5.4). However, XIP levels found in flour did not follow this trend. In flour highest XIP levels were seen in Alsen, while the lowest were for Lolo. In all the genotypes, bran contained higher levels of XIP than did flour (ca. 2.5 fold increase) which was in agreement with the previous published data (Gebruers et al., 2010). As seen in Figure 5.4 (a) there was no evident relationship between the bran XIP levels and location indicating that there was no significant difference between locations for bran XIP levels $(p<005)$. This can be confirmed by non-significant $F$-value obtained for locations for bran XIP levels in the ANOVA table (Table 5.7) $(p<0.05)$. The differences for XIP levels in bran and flour between genotypes were significant at $1 \%$ and $0.1 \%$ level of significance respectively. However, similar to TAXI, there was no significant difference between bran XIP activity in the two classes of HRSW and HWSW at 5\% level of significance. But the difference between HRSW and HWSW in flour XIP activity was significant $(p<0.001)$. 
Table 5.7. Combined Analysis of Variance (genotype fixed; location random) of bran TAXI, XIP and flour XIP activity levels.

\begin{tabular}{|c|c|c|c|c|c|c|}
\hline \multirow{3}{*}{$\begin{array}{l}\text { Source } \\
\text { Location (L) }\end{array}$} & \multicolumn{6}{|c|}{ F Value } \\
\hline & \multicolumn{2}{|c|}{ Bran TAXI } & \multicolumn{2}{|c|}{ Bran XIP } & \multicolumn{2}{|c|}{ Flour XIP } \\
\hline & 3.44 & ns & 4.02 & ns & 32.66 & $* * *$ \\
\hline Rep(Location) & 3.22 & $*$ & 1.36 & ns & 0.79 & ns \\
\hline Genotype (G) & 12.04 & $* * *$ & 4.28 & $* *$ & 9.79 & $* * *$ \\
\hline $\mathrm{L}^{*} \mathrm{G}$ & 7.1 & $* * *$ & 2.6 & $* *$ & 3.51 & $* * *$ \\
\hline Red (R) vs White (W) & 0.61 & ns & 0.3 & ns & 90.11 & $* * *$ \\
\hline $\mathrm{R}$ vs W-Carrington & 10.04 & $* *$ & 0.13 & ns & 32.92 & $* * *$ \\
\hline R vs W- Casselton & 4.56 & $*$ & 1.11 & ns & 37.95 & $* * *$ \\
\hline R vs W- Prosper & 0.15 & ns & 3.24 & ns & 40.57 & $* * *$ \\
\hline
\end{tabular}

*** $P$-value $<0.001 ; * * P$-value $<0.01 ; * P$-value $<0.05$; ns non-significant

Overall, XIP levels in bran were about three times higher than TAXI levels.This was in agreement with the previous published data (Dornez et al., 2006a; Dornez et al., 2008). However, flour XIP levels were approximately eight times higher than TAXI levels in contrast to what was observed by Bonnin et al. (2005). They observed only a three fold increase in XIP level in flour compared to TAXI in his studies using 20 french wheat cultivars. Similar to our results, the occurance of higher levels of xylanase inhibitors in the outer grain tissue layers of the wheat grain compared to endosperm has been demonstrated earlier (Dornez et al., 2006c; Croes et al., 2009). The highest concentrations of TAXI and XIP are found in the aleuron layer of the wheat grain (Croes et al., 2009). Even thouth the TAXI and XIP concentration are lowest in the endosperm, on a grain basis, it contains almost half of the total TAXI and XIP in the grain. This 
spatial distribution of having high inhibitor levels in the outer layers of the grain has been presented as evidence for the role of TAXI and XIP in plant defence (Dornez et al., 2010).
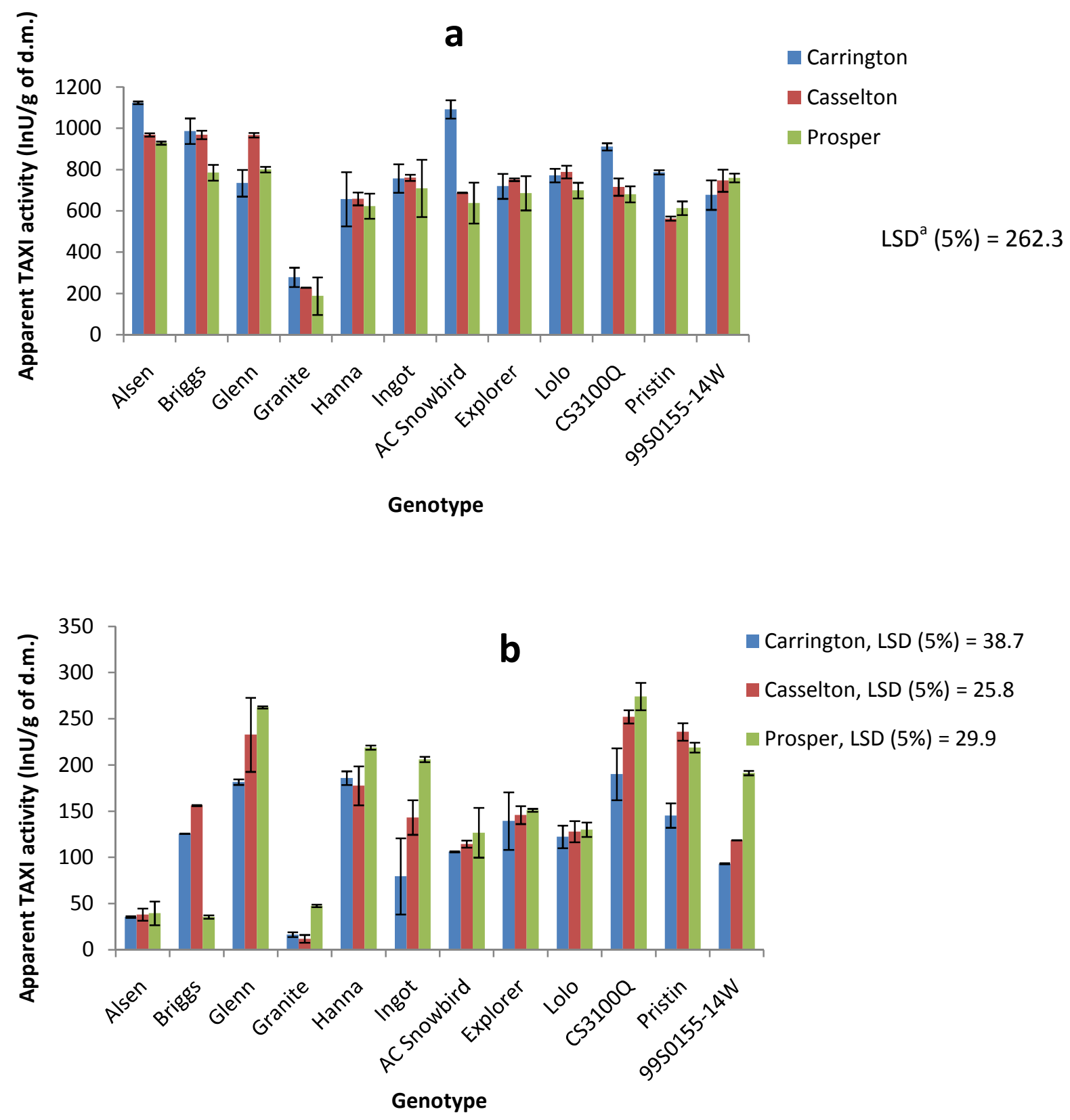

Figure 5.3. Variability of TAXI activity in bran (a) and flour (b) of different genotypes at different locations (Carrington, Casselton, and Prosper). LSD, least significant difference. InU, inhibition units. $\mathrm{LSD}^{\mathrm{a}}$, LSD between genotypes within same location. 

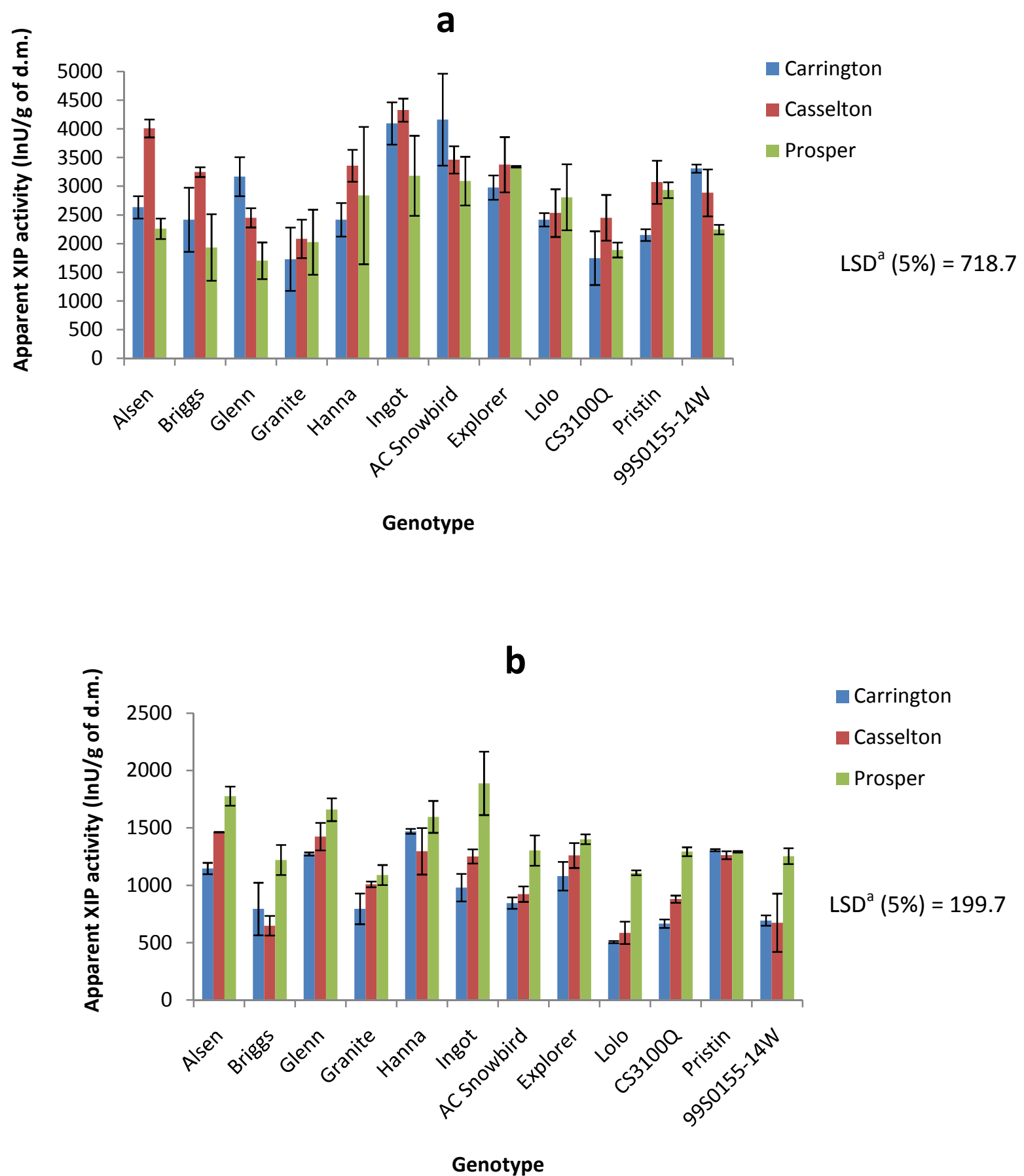

Figure 5.4. Variability of XIP activity in bran (a) and flour (b) of different genotypes at different locations (Carrington, Casselton, and Prosper). LSD, least significant difference. InU, inhibition units. LSD ${ }^{\text {a }}$ LSD between genotypes within same location. 
Table 5.8 presents the xylanase activity, TAXI activity and XIP activity in 12 genotype means at three different locations. TAXI and XIP activity in bran in the three locations are not significantly different $(p<0.05)$. However, based on the values presented, there is a tendency for lower inhibitor activity in Prosper than the other two locations. At first, this seem to contrast with the results of others (Igawa et al., 2004; Igawa et al., 2005) who indicated that TAXI and XIP type genes are induced by plant disease. Thus, we would expect to see higher levels of TAXI and XIP activity in Prosper than in Carrington due to relatively higher precipitation in prosper. However, if higher microbial pressure is present in Prosper the grains would contain higher levels of microbial xylanase. As higher amount of TAXI and XIP are now involved in inhibiting these microbial xylanase, the measured 'apparent' inhibitor activity level would be low. Thus, our data does not necessarily contradict from what others (Igawa et al., 2004; Igawa et al., 2005) have observed.

Table 5.8. Mean genotype apparent xylanase activity, apparent TAXI activity, and apparent XIP activity in bran and flour in three locations, Carrington, Casselton and Prosper, ND in 2008.

\begin{tabular}{|c|c|c|c|c|c|c|}
\hline \multirow[t]{2}{*}{ Location } & \multicolumn{2}{|c|}{$\begin{array}{l}\text { Apparent xylanase } \\
\text { activity }^{\mathrm{a}} \text { (mU/g d.m.) }\end{array}$} & \multicolumn{2}{|c|}{$\begin{array}{l}\text { Apparent TAXI } \\
\text { activity }^{\mathrm{a}} \text { (InU/g d.m.) }\end{array}$} & \multicolumn{2}{|c|}{$\begin{array}{l}\text { Apparent XIP activity }^{\mathrm{a}} \\
\text { (InU/g d.m.) }\end{array}$} \\
\hline & Bran & Flour & Bran & flour & Bran & flour \\
\hline Carrington & 3.8 & 0.7 & 791.4 & 118.4 & 2768.9 & 963.7 \\
\hline Casselton & 23.4 & 1.9 & 734.1 & 146.2 & 3104.8 & 1056.7 \\
\hline Prosper & 30.6 & 2.4 & 676.2 & 158.5 & 2521.0 & 1407.3 \\
\hline $\operatorname{LSD}^{\mathrm{b}}(5 \%)$ & 3.0 & - & ns & - & ns & 58.9 \\
\hline
\end{tabular}

\footnotetext{
${ }^{\mathrm{a}}$ Values are mean values of 12 genotypes.

${ }^{\mathrm{b}}$ LSD, least significant difference; ns, non-significant.
} 
Contribution from each variable to TAXI activity in wheat bran (Figure 5.5) and XIP activity in bran (Figure 5.6 (a)) and flour (Figure 5.6 (b)) were calculated using SAS (Window Version 6.1) 'MIXED' procedure . Genotype had the highest contribution to bran TAXI activity, accounting for approximately three-fourth of the variability (72\%). Similarly, the largest part of the variability in XIP was also resulting from genotype. Dornez et al. (2008) reported that 77\% of variability in TAXI in wheat whole grain is coming from genotype. Based on the samples we tested Granite had consistently very low TAXI levels in all three locations. This indicates that the contribution from genotype to TAXI activity is very high. Thus TAXI activity levels are largely under genetic control and breeders can aim at achieving high or low TAXI levels in wheat by plant breeding. However, for XIP the genotype contribution to the variability was relatively low (39\% for bran and $44 \%$ for flour). Gebruers et al. (2010) observed 31\% genotype contribution to bran and flour XIP activity. Based on our data ca. $40 \%$ of variation in XIP activity is related to genotype. However, there is a relatively large contribution coming from the $\mathrm{L}^{*} \mathrm{G}$ interaction too. In Bran XIP the contribution from residual effect was quite large (28\%). However, others also reported large (ca. 10\%) residual contributions for variability in XIP activity (Dornez et al., 2008; Gebruers et al., 2010). Igawa et al. (2005) demonstrated that in wheat xylanase inhibitor gene, Xip-I, but not Taxi-I, is significantly induced by biotic and abiotic signals that trigger plant defense. Our results are consistent with this observation. Igawa suggested that genes for TAXI can be considered as pre-existing defense genes. Thus the effect of genotype for their variability is much higher than for XIP. On the other hand XIP is heavily inducible by environmental factors which can help explain the large contribution from $L * G(11-22 \%)$ for XIP. Moreover, the relatively large contribution from $\mathrm{L}^{*} \mathrm{G}$ indicate that XIP levels in wheat is not a very stable breeding parameter. 


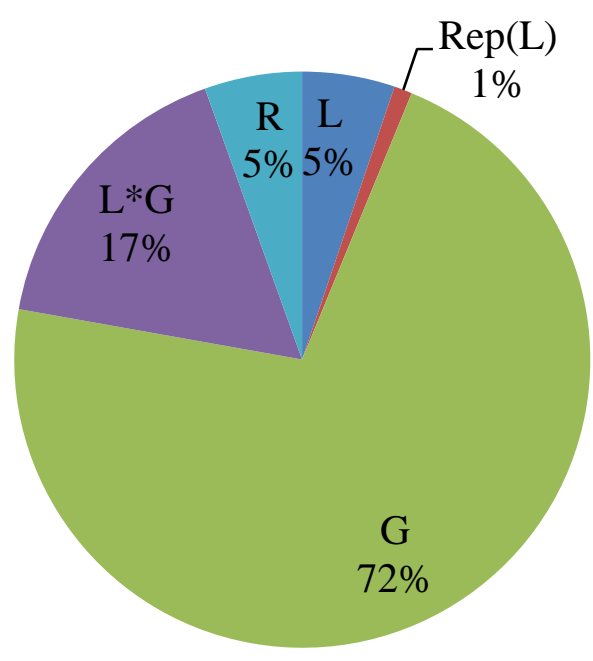

Figure 5.5. Contribution (\%) of genotype $(\mathrm{G})$, location $(\mathrm{L})$, interaction between $\mathrm{L}$ and $\mathrm{G}(\mathrm{L} * \mathrm{G})$, replicates by $L(\operatorname{Rep}(\mathrm{L}))$ and the residual variability that cannot be explained by above variables (R) to the variation in apparent TAXI activity of wheat bran.

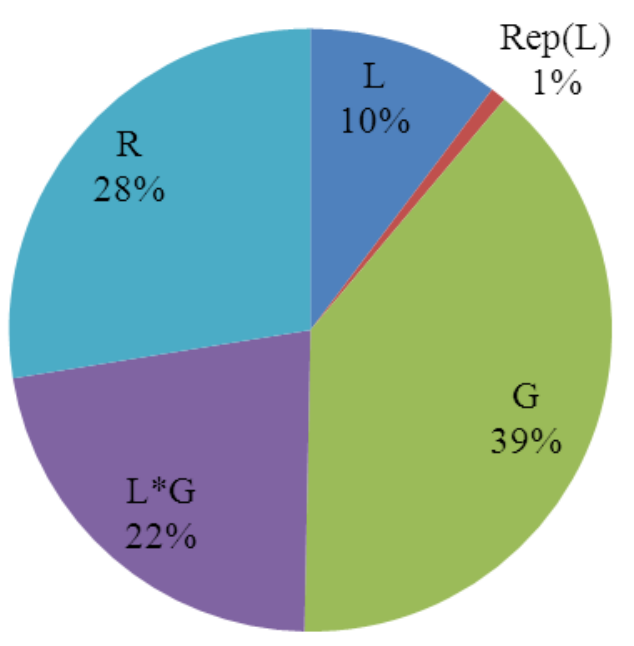

a

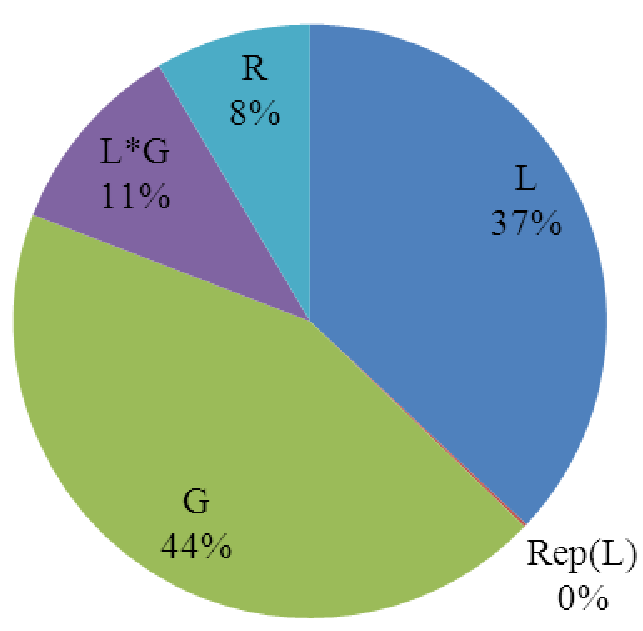

b

Figure 5.6. Contribution (\%) of genotype $(\mathrm{G})$, location $(\mathrm{L})$, interaction between $\mathrm{L}$ and $\mathrm{G}(\mathrm{L} * \mathrm{G})$, replicates by $L(\operatorname{Rep}(\mathrm{L}))$ and the residual variability that cannot be explained by above variables (R) to the variation in apparent XIP activity of wheat bran (a) and flour (b). 
5.6. Correlation between Xylanase Activity, Xylanase Inhibition Activity, and Other Parameters Tables 5.9, 5.10 and 5.11 summarize the correlation analysis data on xylanase activity, xylanase inhibition activity, and other parameters (TOT-AX, A/X ratio, protease activity, $\alpha-$ amylase activity and protein content) for 12 wheat genotypes in Carrington, Casselton and Prosper respectively. In all three locations, bran xylanase activity was strongly correlated with flour xylanase activity. High xylanase activity in bran was accompanied by high xylanase activity in flour. No other correlation was observed between two parameters consistently in all three locations. Interestingly, in Casselton there was a significant positive correlation between $\alpha$ amylase and bran xylanase activity $(p<0.01)$, whole meal xylanase activity $(p<0.01)$, and flour xylanase activity $(p<0.05)$. We did not expect to see such correlation between these two enzymes because xylanase is not only produced by plant but also by microbes residing on the grain too. 
Table 5.9. Correlation coefficients among parameters ${ }^{\mathrm{a}}$ tested in wheat genotypes in Carrington, ND in 2008.

\begin{tabular}{|c|c|c|c|c|c|c|c|c|c|c|c|c|}
\hline & Bxy & Fxy & Wxy & Btaxi & Ftaxi & Bxip & Fxip & Bax & $\mathrm{Ba} / \mathrm{x}$ & Protease $^{\mathrm{b}}$ & $\begin{array}{r}\alpha- \\
\text { Amylase }^{b}\end{array}$ & Protein $^{\mathrm{b}}$ \\
\hline Bxy & - & $0.787^{* *}$ & $0.80^{* *}$ & 0.21 & 0.46 & -0.32 & 0.05 & -0.02 & 0.23 & -0.26 & 0.45 & -0.47 \\
\hline Fxy & & - & 0.88 & 0.20 & 0.38 & -0.25 & -0.29 & -0.18 & 0.30 & -0.23 & 0.23 & -0.31 \\
\hline Wxy & & & - & -0.01 & 0.29 & -0.18 & -0.07 & -0.11 & 0.35 & -0.48 & 0.37 & -0.10 \\
\hline Btaxi & & & & - & 0.15 & 0.32 & -0.02 & 0.03 & -0.16 & 0.30 & -0.48 & -0.17 \\
\hline Ftaxi & & & & & - & -0.11 & 0.28 & 0.13 & 0.24 & -0.21 & 0.00 & -0.46 \\
\hline Bxip & & & & & & - & 0.05 & 0.17 & -0.44 & -0.11 & $-0.63 *$ & 0.13 \\
\hline Fxip & & & & & & & - & 0.11 & 0.41 & -0.11 & 0.31 & 0.41 \\
\hline Bax & & & & & & & & - & -0.46 & -0.52 & 0.26 & -0.21 \\
\hline $\mathrm{Ba} / \mathrm{x}$ & & & & & & & & & - & -0.12 & 0.36 & 0.35 \\
\hline Protease $^{b}$ & & & & & & & & & & - & -0.38 & 0.05 \\
\hline$\alpha$-Amylase ${ }^{\mathrm{b}}$ & & & & & & & & & & & - & 0.031 \\
\hline Protein $^{\mathrm{b}}$ & & & & & & & & & & & & - \\
\hline
\end{tabular}

*** $P$-value $<0.0001 ; * * P$-value $<0.001 ; * P$-value $<0.05$

${ }^{\mathrm{a}}$ The abbreviations used for each parameter is as follows, bran xylanase, Bxy; flour xylanase, Fxy; Whole meal xylanase, Wxy; Bran TAXI, Btaxi, flour TAXI,

Ftaxi; bran XIP, Bxip; flour XIP, Fxip; bran TOT-AX, Bax; bran arabinose to xylose ratio, Ba/x.

${ }^{\mathrm{b}}$ Data for protease, $\alpha$-Amylase and protein were adopted from Lu (2011). 
Table 5.10. Correlation coefficients among parameters ${ }^{\mathrm{a}}$ tested in wheat genotypes in Casselton, ND in 2008.

\begin{tabular}{|c|c|c|c|c|c|c|c|c|c|c|c|c|}
\hline & Bxy & Fxy & Wxy & Btaxi & Ftaxi & Bxip & Fxip & Bax & $\mathrm{Ba} / \mathrm{x}$ & Protease $^{\mathrm{b}}$ & $\begin{array}{r}\alpha- \\
\text { Amylase }^{\mathrm{b}}\end{array}$ & Protein ${ }^{b}$ \\
\hline Bxy & - & $0.91 * * *$ & $0.94 * * *$ & -0.53 & -0.03 & $-0.62^{*}$ & -0.21 & -0.48 & $0.59^{*}$ & -0.39 & $0.72 * *$ & -0.10 \\
\hline Fxy & & - & $0.93^{* * *}$ & -0.36 & -0.01 & -0.48 & -0.41 & -0.49 & 0.50 & -0.17 & $0.68^{*}$ & -0.38 \\
\hline Wxy & & & - & -0.54 & -0.13 & -0.46 & -0.23 & -0.50 & 0.43 & -0.25 & $0.73 * *$ & -0.17 \\
\hline Btaxi & & & & - & 0.27 & 0.39 & 0.06 & -0.01 & -0.08 & 0.01 & -0.30 & -0.27 \\
\hline Ftaxi & & & & & - & -0.14 & 0.08 & 0.19 & 0.43 & 0.18 & 0.28 & -0.33 \\
\hline Bxip & & & & & & - & 0.38 & 0.09 & -0.50 & 0.21 & -0.28 & -0.08 \\
\hline Fxip & & & & & & & - & -0.22 & 0.10 & -0.08 & -0.18 & 0.34 \\
\hline Bax & & & & & & & & - & -0.45 & 0.27 & -0.34 & 0.21 \\
\hline $\mathrm{Ba} / \mathrm{x}$ & & & & & & & & & - & -0.21 & 0.45 & 0.10 \\
\hline Protease $^{\mathrm{b}}$ & & & & & & & & & & - & -0.45 & -0.24 \\
\hline$\alpha$-Amylase ${ }^{b}$ & & & & & & & & & & & - & -0.27 \\
\hline Protein $^{b}$ & & & & & & & & & & & & - \\
\hline
\end{tabular}

*** $P$-value $<0.0001 ; * * P$-value $<0.001 ; * P$-value $<0.05$

${ }^{\mathrm{a}}$ The abbreviations used for each parameter is as follows, bran xylanase, Bxy; flour xylanase, Fxy; Whole meal xylanase, Wxy; Bran TAXI, Btaxi, flour TAXI,

Ftaxi; bran XIP, Bxip; flour XIP, Fxip; bran TOT-AX, Bax; bran arabinose to xylose ratio, Ba/x.

${ }^{\mathrm{b}}$ Data for protease, $\alpha$-amylase and protein were adopted from Lu (2011). 
Table 5.11. Correlation coefficients among parameters ${ }^{\mathrm{a}}$ tested in wheat genotypes in Prosper, ND in 2008.

\begin{tabular}{|c|c|c|c|c|c|c|c|c|c|c|c|c|}
\hline & Bxy & Fxy & Wxy & Btaxi & Ftaxi & Bxip & Fxip & Bax & $\mathrm{Ba} / \mathrm{x}$ & Protease $^{\mathrm{b}}$ & $\begin{array}{r}\alpha- \\
\text { Amylase }^{\mathrm{b}}\end{array}$ & Protein $^{\mathrm{b}}$ \\
\hline Bxy & - & $0.91 * * *$ & $0.96 * * *$ & $-0.63^{*}$ & -0.12 & 0.02 & $-0.73 * *$ & -0.47 & 0.13 & -0.02 & 0.25 & -0.44 \\
\hline Fxy & & - & $0.93 * * *$ & -0.45 & -0.08 & 0.29 & $-0.68^{*}$ & -0.41 & 0.02 & 0.17 & 0.23 & $-0.66^{*}$ \\
\hline Wxy & & & - & -0.56 & 0.00 & 0.18 & $-0.67 *$ & -0.39 & 0.10 & 0.10 & 0.35 & -0.54 \\
\hline Btaxi & & & & - & 0.13 & -0.04 & 0.50 & -0.01 & -0.20 & -0.29 & -0.12 & -0.17 \\
\hline Ftaxi & & & & & - & 0.06 & 0.25 & 0.22 & -0.00 & 0.26 & 0.28 & -0.21 \\
\hline Bxip & & & & & & - & 0.16 & 0.38 & 0.10 & $0.82 * *$ & 0.10 & -0.34 \\
\hline Fxip & & & & & & & - & 0.32 & 0.16 & 0.01 & -0.45 & 0.40 \\
\hline Bax & & & & & & & & - & 0.09 & 0.42 & 0.38 & 0.20 \\
\hline $\mathrm{Ba} / \mathrm{x}$ & & & & & & & & & - & -0.10 & -0.11 & 0.45 \\
\hline Protease $^{b}$ & & & & & & & & & & - & 0.15 & -0.20 \\
\hline$\alpha$-Amylase ${ }^{\mathrm{b}}$ & & & & & & & & & & & - & -0.38 \\
\hline Protein $^{b}$ & & & & & & & & & & & & - \\
\hline
\end{tabular}

*** $P$-value $<0.0001 ; * * P$-value $<0.001 ; * P$-value $<0.05$

${ }^{\mathrm{a}}$ The abbreviations used for each parameter is as follows, bran xylanase, Bxy; flour xylanase, Fxy; Whole meal xylanase, Wxy; Bran TAXI, Btaxi, flour TAXI,

Ftaxi; bran XIP, Bxip; flour XIP, Fxip; bran TOT-AX, Bax; bran arabinose to xylose ratio, Ba/x.

${ }^{\mathrm{b}}$ Data for protease, $\alpha$-Amylase and protein were adopted from Lu (2011). 


\section{CONCLUSIONS}

In any enzyme related system the three key contributors involved are the substrate, the enzyme and the inhibitor. In our study these contributors were AX, xylanase and xylanase inhibitors respectively (Figure 6.1). Thus, we studied the variability of each of these three contributors in 12 hard spring wheat genotypes consisting of six hard red spring wheat and six hard white wheat classes, in relation to the effect of growing location (L), genotype (G), and location by genotype $\left(\mathrm{L}^{*} \mathrm{G}\right)$ interaction.



Figure 6.1. Overall representation of this study (diagram of wheat kernel adopted from http://pantryparatus.com/blog/whole_wheat/).

The first contributor, AX are an important constituent in grain processing. Even though they are a minor constituent of the grain, their water holding capacity and viscosity properties enforce considerable impact on the functional properties of the grain based product processing. Furthermore, consumption of AX has been associated with beneficial health effects in humans (Garcia et al., 2006). Within our sample set, Lolo had the lowest TOT-AX in bran (14.99\%) while Explorer had the highest TOT-AX in bran (27.96\%). The high TOT-AX levels obtained 
for Explorer suggests that it has high TOT-AX levels compared to what is reported in the literature for spring wheat genotypes. Thus Explorer can be a potential genotype to be used in breeding or in product processing that concern achieving high levels of AX. Based on our data there was no significant difference in TOT-AX among the 12 genotypes $(p<0.05)$ (Table 5.3). However, there was a significant difference in TOT-AX among the two wheat classes, HRSW and HWSW $(P<0.05)$. Overall, HWSW had higher TOT-AX compared to HRSW. The substitution pattern of $\mathrm{AX}$ is an important factor in $\mathrm{AX}$ since it influences the shape, solubility, and molecular characteristics of the AX polymer. We studied the $\mathrm{A} / \mathrm{X}$ ratio of our sample to get an idea about the degree of substitution in AX. All of the genotypes we studied had high A/X ratios indicating a high level of arabinose substitution in AX. There were significant differences in $\mathrm{A} / \mathrm{X}$ ratio among genotypes $(\mathrm{P}<0.05)$ (Table 5.2), which indicates that variations in substitution pattern in AX are genotype dependent. However, there was no significant difference in A/X ratio among the HRSW and HWSW classes. The arabinose substitution pattern of AX was further studied in four selected genotypes (Granite and Ingot to represent HRSW, and Lolo and 99SO155-14w to represent HWSW) from three locations using ${ }^{1} \mathrm{H}-\mathrm{NMR}$. The spectrum consists of two distinct groups of signals. The resonances occurring at the range of $84.4-4.7 \mathrm{ppm}$ had been attributed to the anomeric protons of $\alpha$-L-arabinofuranosyl (Hoffmann et al., 1992). The resonances at the region $\delta 5.2$ to $5.4 \mathrm{ppm}$ have been attributed to the anomeric protons of $\beta$ D-xylopyranosyl residues. Ingot and Lolo had a tendency of having high proportions of disubstituted xylose with neighboring di-substituted xylose in all three locations indicating high level of di-substitution along the xylan backbone. The overall spectral data (Table 5.4) indicated that the substitution pattern favors di-substitution over mono-substitution which was supportive 
of the comments made by others (Dervilly-Pinel et al., 2004; Gruppen et al., 1993) that suggested that the biosynthetic mechanism of AX substitution favors di-substitution.

The variability of the second key contributor, xylanase in the wheat samples was studied (Figure 6.1). Wheat bran, flour and whole meal was assayed separately. The xylanase activity was mainly concentrated in the wheat bran. In bran, highest average xylanase activity was seen in HWSW genotype Lolo, while the lowest average xylanase activity was seen in HRSW genotype Ingot. There was a significant difference among the locations, genotypes and location by genotype interaction for xylanase activity levels in bran and whole meal $(p<0.05)$. Also, there is a significant difference between the HRSW and HWSW genotypes for xylanase activity $(p<0.05)$. From the three locations, Prosper, which had relatively higher precipitation than Carrington, also had higher xylanase activity in bran. This can be due to the higher microbial pressure in Prosper. We calculated the contribution from each variable to xylanase activity in wheat bran and whole meal. Approximately, $30 \%$ of the variation can be related to genotype and $10-25 \%$ variation comes from $\mathrm{L} * \mathrm{G}$ interaction. The relative high level of $\mathrm{L} * \mathrm{G}$ interaction term indicate that bran xylanase level is not a very stable breeding parameter.

The third contributor (Figure 6.1), xylanase inhibitors was also studied to evaluate the effect of genotype, growing location and $\mathrm{L}^{*} \mathrm{G}$ interaction on its variability in hard spring wheat. The two most abundant xylanase inhibitors found in wheat, TAXI and XIP were studied. Levels of TAXI activity and XIP activity were higher in bran than in flour, suggesting these inhibitors are concentrated in the outer layers of the grain. On average, the highest level of TAXI in the bran was seen in Alsen while the lowest was for Granite. However, in flour, Granite had the lowest levels of TAXI but Alsen also had considerably low levels. In the case of XIP, on average, highest bran XIP levels were seen in Ingot while lowest XIP levels were seen in Granite. 
However, XIP levels found in flour did not follow this trend. In flour highest XIP levels were seen in Alsen, while the lowest were for Lolo. Overall XIP levels in bran were about three times higher than TAXI levels. However, in the flour XIP levels were about eight times higher than TAXI levels in contrast to what was observed by Bonnin et al. (2005). The contribution from each variable to TAXI activity was calculated. Genotype contributed $72 \%$ to the TAXI activity variability indicating that the TAXI activity in wheat bran is hugely under genetic control. For variability of XIP activity, the genotype contribution was only $39 \%$ and $44 \%$ for bran and flour, respectively. Also, the contribution from $\mathrm{L}^{*} \mathrm{G}$ interaction to XIP activity was high ranging from $22 \%$ in bran to $11 \%$ in flour. Thus XIP is thought to be a less stable breeding parameter than TAXI. 


\section{FUTURE RESEARCH}

Similar to our findings, others have also failed to find a relationship between the TOTAX level and wheat variety (Andersson et al., 1993; Dornez et al., 2008). However, in contrast to TOT-AX level, WE-AX level in wheat has been found to be strongly under genetic control (Dornez et al., 2008). Thus further research on the WE-AX in our sample might help identify genotypes that can be helpful for breeders to breed for low/ high WE-AX levels containing genotypes.

The wheat samples could be further used in processes such as bread baking to identify how the changes in AX level, xylanase activity and xylanase inhibition activity levels affect processing parameters.

Ingot and the experimental line $99 \mathrm{~S} 0155-14 \mathrm{~W}$ have a tendency towards low xylanase activity while Granite and Lolo have a tendency towards high xylanase activity in all the three locations. Thus, these genotypes can be suitable candidates for further research.

As TAXI activity in wheat seems to be largely under genetic control, breeding for genotypes that are either low or high in TAXI that compliments its end use seems a promising direction for plant breeders. We have identified Granite as a suitable genotype for low TAXI activity.

Within our study we only looked into the effect of growing location on AX, xylanase activity level and xylanase inhibitor activity levels in wheat. However, repeating the experimental design in same location in different years will help better calculate the environmental contribution to the variability of above parameters. 


\section{REFERENCE LIST}

AACC International. 1999. Method 44-15.02 Moisture - Air-Oven Methods, Approved

November 3rd 1999. Approved Methods of Analysis (10 ${ }^{\text {th }}$ ed). American Association of Cereal Chemists, St. Paul, MN.

Andersson,R., E.Westerlund, A.C.Tilly, and P.Aman. 1993. Natural Variations in the Chemical Composition of White Flour. Journal of Cereal Science 17:183-189.

Badal,C. 2002. Production, purification and properties of xylanase from a newly isolated Fusarium proliferatum. Process Biochemistry 37:1279-1284.

Bedford,M.R., and H.Schulze. 1998. Exogenous enzymes for pigs and poultry. Nutrition Research Reviews 11:91-114.

Benjavongkulchai,E., and M.S.Spencer. 1986. Purification and characterization of barleyaleurone xylanase. Planta 169:415-419.

Bhat,M.K. 2000. Cellulases and related enzymes in biotechnology. Biotechnology Advances $18: 355-383$.

Biely,P., M.Vrsanska, M.Tenkanen, and D.Kluepfel. 1997. Endo-beta-1,4-xylanase families: differences in catalytic properties. Journal of Biotechnology 57:151-166.

Blakeney,A.B., P.J.Harris, R.J.Henry, and B.A.Stone. 1983. A simple and rapid preperation of alditol acetates for monosaccharide analysis. Carbohydrate Research 113:291-299. 
Bonnin,E., S.p.Daviet, K.Gebruers, J.A.Delcour, A.Goldson, N.Juge, and L.Saulnier. 2005. Variation in the levels of the different xylanase inhibitors in grain and flour of 20 French wheat cultivars. Journal of Cereal Science 41:375-379.

Carbohydrate active enzyme CAZY server. 2012. Available at http://www.cazy.org/GlycosideHydrolases.html (accessed February 10, 2012).

Chen,N.J., and R.E.Paull. 2003. Endoxylanase expressed during papaya fruit ripening: purification, cloning and characterization. Functional Plant Biol. 30:433-441.

Christophersen,C., E.Andersen, T.S.Jakobsen, and P.Wagner. 1997. Xylanases in Wheat Separation. Starch 49:5-12.

Cleemput,G., M.van Oort, M.Hessing, M.E.F.Bergmans, H.Gruppen, P.J.Grobe, and J.A.Delcour. 1995. Variation in the degree of D-Xylose substitution in arabinoxylans extracted from a European wheat flour. Journal of Cereal Science 22:73-84.

Collins,T., C.Gerday, and G.Feller. 2005. Xylanases, xylanase families and extremophilic xylanases. FEMS Microbiology Reviews 29:3-23.

Courtin,C.M., and J.A.Delcour. 2002. Arabinoxylans and Endoxylanases in Wheat Flour Breadmaking. Journal of Cereal Science 35:225-243.

Courtin,C.M., W.Gys, K.Gebruers, and J.A.Delcour. 2005. Evidence for the Involvement of Arabinoxylan and Xylanases in Refrigerated Dough Syruping. Journal of Agricultural and Food Chemistry 53:7623-7629. 
Courtin,C.M., W.Gys, K.Gebruers, and J.A.Delcour. 2005. Evidence for the Involvement of Arabinoxylan and Xylanases in Refrigerated Dough Syruping. Journal of Agricultural and Food Chemistry 53:7623-7629.

Courtin,C.M., A.Roelants, and J.A.Delcour. 1999. Fractionation and Reconstitution Experiments Provide Insight into the Role of Endoxylanases in Bread-Making. Journal of Agricultural and Food Chemistry 47:1870-1877.

Croes,E., K.Gebruers, N.Luyten, J.A.Delcour, and C.M.Courtin. 2009. Immunoblot Quantification of Three Classes of Proteinaceous Xylanase Inhibitors in Different Wheat (Triticum aestivum) Cultivars and Milling Fractions. Journal of Agricultural and Food Chemistry 57:1029-1035.

Dash,C., A.Ahmad, D.Nath, and M.Rao. 2001. Novel Bifunctional Inhibitor of Xylanase and Aspartic Protease: Implications for Inhibition of Fungal Growth. Antimicrobial Agents and Chemotherapy 45:2008-2017.

Debyser,W., J.A.Delcour, and G.Derdelinckx. 1997. Arabinoxylan solubilization and inhibition of the barley malt xylanolytic system by wheat during mashing with wheat wholemeal adjunct: evidence for a new class of enzyme inhibitors in wheat. Journal of the American Society of Brewing Chemists 55:153-156.

Debyser,W., W.J.Peumans, E.J.M.Damme, and J.A.Delcour. 1999. Triticum aestivum xylanase inhibitor (TAXI), a new class of enzyme inhibitor affecting breadmaking performance. Journal of Cereal Science 30:39-43. 
Dekker,R.F., and G.N.Richards. 1976. Hemicellulose: their occurrence, purification properties and mode of action. Adv. Carbohydr. Chem. Biochem. 32:277-352.

Delcour,J.A., and R.C.Hoseney. 2010a. Dry Milling. p. 121-137. In Jan A Delcour, and R.Carl Hoseney (ed.) Principles of Cereal Science and Technology. AACC International, Inc., MN.

Delcour,J.A., and R.C.Hoseney. 2010b. Structure of Cereals. p. 1-22. In Jan A Delcour, and R.Carl Hoseney (ed.) Principles of Cereal Science and Technology. AACC International, Inc., MN.

Delcour,J.A., and R.C.Hoseney. 2010c. Minor constituents. p. 71-84. In Jan A Delcour, and R.Carl Hoseney (ed.) Principles of Cereal Science and Technology. AACC International, Inc., MN.

Dervilly-Pinel,G., V.Tran, and L.Saulnier. 2004. Investigation of the distribution of arabinose residues on the xylan backbone of water-soluble arabinoxylans from wheat flour. Carbohydrate Polymers 55:171-177.

Dong,X. 2010. Isolation and characterization of xylanase from Fusarium graminearum. North Dakota State University Ph.D., North Dakota State University, North Dakota, United States.

Dornez,E., E.Croes, K.Gebruers, B.D.Coninck, B.P.A.Cammue, J.A.Delcour, and C.M.Courtin. 2010. Accumulated Evidence Substantiates a Role for Three Classes of Wheat Xylanase Inhibitors in Plant Defense. Critical Reviews in plant Science 244-264. 
Dornez,E., K.Gebruers, J.Delcour, and C.Courtin. 2009. Grain-associated xylanases: occurrence, variability, and implications for cereal processing. Trends in food science \& technology. 20:495510.

Dornez,E., K.Gebruers, I.J.Joye, B.De Ketelaere, J.Lenartz, C.Massaux, B.Bodson, J.A.Delcour, and C.M.Courtin. 2008. Effects of genotype, harvest year and genotype-by-harvest year interactions on arabinoxylan, endoxylanase activity and endoxylanase inhibitor levels in wheat kernels. Journal of Cereal Science 47:180-189.

Dornez,E., I.J.Joye, K.Gebruers, J.A.Delcour, and C.M.Courtin. 2006a. Wheat-KernelAssociated Endoxylanases Consist of a Majority of Microbial and a Minority of Wheat Endogenous Endoxylanases. Journal of Agricultural and Food Chemistry 54:4028-4034.

Dornez,E., I.J.Joye, K.Gebruers, J.Lenartz, C.Massaux, B.Bodson, J.A.Delcour, and C.M.Courtin. 2006b. Insight into variability of apparent endoxylanase and endoxylanase inhibitor levels in wheat kernels. J. Sci. Food Agric. 86:1610-1617.

Dornez,E., K.Gebruers, S.Wiame, J.A.Delcour, and C.M.Courtin. 2006c. Insight into the Distribution of Arabinoxylans, Endoxylanases, and Endoxylanase Inhibitors in Industrial Wheat Roller Mil Streams. Journal of Agricultural and Food Chemistry 54:8521-8529.

Dupont,F.M., and S.B.Altenbach. 2003. Molecular and biochemical impacts of environmental factors on wheat grain development and protein synthesis. Journal of Cereal Science 38:133-146.

Fierens,E. 2007a. TLXI, athaumatin-like xylanase inhibitor: isolation, characterisation and comparision with other wheat (Triticum aestivum L.) xylanase inhibiting proteins. Katholieke Universiteieit Leuven Ph.D., Katholiele Universiteit, Leuven, Belgium. 
Fierens,E. 2007b. TLXI, a novel type of Xylanase inhibitor from wheat (Triticum aestivum) belonging to the thaumatin family. Biochem Journal 365:773-781.

Fierens,K., K.Brijs, C.M.Courtin, K.Gebruers, H.Goesaert, G.Raedschelders, J.Robben, S.Van Campenhout, G.Volckaert, and J.A.Delcour. 2003. Molecular identification of wheat endoxylanase inhibitor TAXI-I, member of a new class of plant proteins. FEBS Letters 540:259263.

Fincher, G. B. and Stone, B. A. Cell walls and their components in cereal grain technology. Advances in Cereal Science and Technology 8, 207-295. 1-1-1986. Dep. of Biochem., La Trobe Univ., Bundoora, Victoria 3083, Australia.

Fox,A., S.L.Morgan, and J.Gilbart. 1989. Preperation of alditol acetates and their analysis by gas chromatography and mass spectroscory. p. 87-125. In C.J.Biermann, and G.D. McGinnins (ed.) Analysis of Carbohydrates by GLC and MS. CRC Prsaa, Inc., Florida.

Frederix,S.A., C.M.Courtin, and J.A.Delcour. 2004a. Substrate selectivity and inhibitor sensitivity affect xylanase functionality in wheat flour gluten-starch separation. Journal of Cereal Science 40:41-49.

Frederix,S.A., K.E.Van hoeymissen, C.M.Courtin, and J.A.Delcour. 2004b. Water-Extractable and Water-Unextractable Arabinoxylans Affect Gluten Agglomeration Behavior during Wheat Flour Gluten Starch Separation. Journal of Agricultural and Food Chemistry 52:7950-7956. 
Garcia,A.L., B.Otto, S.C.Reich, M.O.Weickert, J.Steiniger, A.Machowetz, N.N.Rudovich, M.Mohlig, N.Katz, M.Speth, F.Meuser, J.Doerfer, H.-J.F.Zunft, A.H.F.Pfeiffer, and C.Koebnick. 2006. Arabinoxylan consumption decreases postprandial serum glucose, serum insulin and plasma total ghrelin response in subjects with impaired glucose tolerance. Eur J Clin Nutr 61:334-341.

Gebruers,K., W.Debyser, H.Goesaert, P.Proost, J.Van Damme, and J.A.Delcour. 2001. Triticum aestivum L. endoxylanase inhibitor (TAXI) consists of two inhibitors, TAXI I and TAXI II, with different specificities. Biochemical Journal 353:239-244.

Gebruers,K., E.Dornez, Z.Bedo, M.Rakszegi, C.M.Courtin, and J.A.Delcour. 2010. Variability in Xylanase and Xylanase Inhibition Activities in Different Cereals in the HEALTHGRAIN Diversity Screen and Contribution of Environment and Genotype to This Variability in Common Wheat. Journal of Agricultural and Food Chemistry 58:9362-9371.

Geissman,T., andH.Neukom. 1973. A note on ferulic acid as a constituent of water insoluble pentosans of wheat flour. Cereal Chemistry 50:414-416.

Goesaert,H. 2002. Occurance, purification and properties of endoxylanase inhibitors in different cereals. PhD Faculteit Bio-Ingeieurswetenschappen, Katholiele Universiteit, Leuven, Belgium

Goesaert,H., K.Brijs, W.S.Veraverbeke, C.M.Courtin, K.Gebruers, and J.A.Delcour. 2005. Wheat flour constituents: how they impact bread quality, and how to impact their functionality. Trends in Food Science and Technology 16:12-30.

Goesaert,H., C.M.Courtin, J.A.Delcour, K.Gebruers, and K.Brijs. 2003a. XIP-type endoxylanase inhibitors in different cereals. Journal of Cereal Science 38:317-324. 
Goesaert,H., W.Debyser, K.Gebruers, P.Proost, J.Van Damme, and J.A.Delcour. 2001.

Purification and Partial Characterization of an Endoxylanase Inhibitor from Barley. Cereal Chemistry Journal 78:453-457.

Goesaert,H., K.Gebruers, K.Brijs, C.M.Courtin, and J.A.Delcour. 2003b. TAXI Type Endoxylanase Inhibitors in Different Cereals. Journal of Agricultural and Food Chemistry 51:3770-3775.

Goesaert,H., G.Elliott, P.A.Kroon, K.Gebruers, C.M.Courtin, J.Robben, J.A.Delcour, and N.Juge. 2004. Occurrence of proteinaceous endoxylanase inhibitors in cereals. Biochimica et Biophysica Acta (BBA) - Proteins \&amp; Proteomics 1696:193-202.

Gooding,M.J. 2009. The wheat crop. p. 19-49. In K.Khan, and P.R. Shewry (ed.) Wheat Chemistry and Technology. AACC International, Minnesota.

Gruppen,H., F.J.M.Kormelink, and A.G.J.Voragen. 1993. Water-unextractable Cell Wall Material from Wheat Flour. 3. A Structural Model for Arabinoxylans. Journal of Cereal Science 18:111-128.

Gys,W., K.Gebruers, J.F.Sorensen, C.M.Courtin, and J.A.Delcour. 2004. Debranning of wheat prior to milling reduces xylanase but not xylanase inhibitor activities in wholemeal and flour. Journal of Cereal Science 39:363-369.

Gys,W., C.M.Courtin, and J.A.Delcour. 2003. Refrigerated Dough Syruping in Relation to the Arabinoxylan Population. Journal of Agricultural and Food Chemistry 51:4119-4125. 
Henrissat,B., M.Claeyssens, P.Tomme, L.Lemesle, and J.P.Mornon. 1989. Cellulase families revealed by hydrophobic cluster analysis. Gene 81:83-95.

Henrissat,B., and P.M.Coutinho. 2001. Classification of glycoside hydrolases and glycosyltransferases from hyperthermophiles. p. 183-201. In W.W.A.Michael (ed.) Methods in Enzymology

Henry,R.J. 1985. A comparison of the non-starch carbohydrates in cereal grains. J. Sci. Food Agric. 36:1243-1253.

Hoffmann,R.A., J.P.Kamerling, and J.F.G.Vliegenthart. 1992. Structural features of a watersoluble arabinoxylan from the endosperm of wheat. Carbohydrate Research 226:303-311.

Igawa,T., T.Ochiai-Fukuda, N.Takahashi-Ando, S.Ohsato, T.Shibata, I.Yamaguchi, and M.Kimura. 2004. New TAXI-type Xylanase Inhibitor Genes are Inducible by Pathogens and Wounding in Hexaploid Wheat. Plant and Cell Physiology 45:1347-1360.

Igawa,T., T.Tokai, T.Kudo, I.Yamaguchi, and M.Kimura. 2005. A wheat xylanase inhibitor gene, Xip-I, but not Taxi-I, is significantly induced by biotic and abiotic signals that trigger plant defense. Bioscience, biotechnology and biochemistry 69:1058-1063.

Iiyama,K., T.B.T.Lam, and B.A.Stone. 1994. Covalent cross-links in the cell wall. Plant physiology 104:315-320.

Izydorczyk,M.S., and C.G.Biliaderis. 1992. Influence of structure on the physicochemical properties of wheat arabinoxylan. Carbohydrate Polymers 17:237-247. 
Kulkarni,N., A.Shendye, and M.Rao. 1999. Molecular and biotechnological aspects of xylanase. FEMS Microbiology Reviews 23:411-456.

Lu,H. 2011. Physicochemical Properties of pre-harvest sprouted hard spring wheat. North Dakota State University M. S., North Dakota State University, North Dakota. United States .

Mares,D.J., and B.A.Stone. 1973. Studies on wheat endosperm. I Chemical composition and ultrastructure of the cell wall. Australian journal of biological sciences 26:793-812.

McCarter,J.D., and G.Stephen Withers. 1994. Mechanisms of enzymatic glycoside hydrolysis. Current Opinion in Structural Biology 4:885-892.

McLauchlan,W.R., M.T.Garcia-Conesa, G.Williamson, M.Roza, P.Ravestein, and J.Maat. 1999. A novel class of protein from wheat which inhibits xylanases. Biochem Journal 338:441-446.

Megazyme International. endo-1,4-ß-D-Xylanase assay procedure. Megazyme International . Availabla at http://secure.megazyme.com/downloads/en/data/T-XAX200.pdf (accessed January 24, 2012).

Meuser,F., and P.Suckow. 1986. Nonstarch polysaccharides. p. 42-61. In J.M.V.Blanshard, P.J. Frazier, and T. Galliard (ed.) Chemistry and Physics of Baking. The Royal Society of Chemistry, London, UK.

Miller,G. 1959. Use of dinitrosalisylic acid reagent for determination of reducing sugars. Analytical Chemistry 31:426-428. 
Mpofu,A., H.D.Sapirstein, and T.Beta. 2006. Genotype and Environmental Variation in Phenolic Content, Phenolic Acid Composition, and Antioxidant Activity of Hard Spring Wheat. Journal of Agricultural and Food Chemistry 54:1265-1270.

Poulsen,C.H., and J.F.Soerensen. Process of forming a refrigerated dough. Patene application no. WO01/52657.

Reilly,P.J. 1981. Xylanase: Structure and Function. p. 111-129. In A.Hollaender (ed.) Trends in the Biology of Fermentation for Fuels and Chemicals. Basic Life Sciences, Plenum Press, New York.

Rouau,X., and A.Surget. 1998. Evidence for the Presence of a Pentosanase Inhibitor in Wheat Flours. Journal of Cereal Science 28:63-70.

Rugg,M.O.P. 2011. Evaluating Hard Red and White Spring Wheat (Triticum Aestivum L.) Genotypes for Tolerance to Pre-harvest Sprouting. North Dakota State University M. S., North Dakota State University, North Dakota, United States.

Rye,C.S., and S.G.Withers. 2000. Glycosidase mechanisms. Current Opinion in Chemical Biology 4:573-580.

Saulnier,L., P.E.Sado, G.Branlard, G.Charmet, and F.Guillon. 2007. Wheat arabinoxylans: Exploiting variation in amount and composition to develop enhanced varieties. Journal of Cereal Science 46:261-281. 
Simmons, S. R, Oelke, E. A., and Anderson, P. M. Growth and development guide for spring wheat. University of Minnasota Extension . 1995. Available at http://www.extension.umn.edu/distribution/cropsystems/dc2547.html (accessed February 5, 2012)

Simpson,D.J., G.B.Fincher, A.H.C.Huang, and V.Cameron-Mills. 2003. Structure and Function of Cereal and Related Higher Plant (1-4)- $\beta$-Xylan Endohydrolases. Journal of Cereal Science 37:111-127.

Simsek,S., and J.B.Ohm. 2009. Structural changes of arabinoxylans in refrigerated dough. Carbohydrate Polymers 77:87-94.

Soerensen,J.F., K.M.Kragh, O.Sibbesen, J.A.Delcour, H.Goesaert, B.Svensson, T.A.Tahir, J.Brufau, A.M.Perez-Vendrell, D.Bellincampi, R.D'Ovidio, L.Camardella, A.Giovane, E.Bonnin, and N.Juge. 2004. Potential role of glycosidase inhibitors in industrial biotechnological applications. Biochimica et Biophysica Acta (BBA) - Proteins \&amp; Proteomics 1696:275-287.

Storsley,J.M., M.S.Izydorczyk, S.You, C.G.Biliaderis, and B.Rossnagel. 2003. Structure and physicochemical properties of $\beta$-glucans and arabinoxylans isolated from hull-less barley. Food Hydrocolloids 17:831-844.

Suzuki,M., A.Kato, N.Nagata, and Y.Komeda. 2002. A Xylanase, AtXyn1, is Predominantly Expressed in Vascular Bundles, and Four Putative Xylanase Genes were Identified in the Arabidopsis thaliana Genome. Plant and Cell Physiology 43:759-767.

Tomme,P., R.A.J.Warren, and N.R.Gilkes. 1995. Cellulose Hydrolysis by Bacteria and Fungi. p. 1-81. In R.K.Poole (ed.) Advances in Microbial Physiology. Academic Press. 
United States Patent and Trademark Office. Available at http://patft.uspto.gov/ (accessed March $5,2012)$

Vathipadiekal,V., and M.Rao. 2004. Inhibition of 1,4-beta-d-Xylan Xylanohydrolase by the Specific Aspartic Protease Inhibitor Pepstatin. Journal of Biological Chemistry 279:4702447033.

Vorwerk,S., S.Somerville, and C.Somerville. 2004. The role of plant cell wall polysaccharide composition in disease resistance. Trends in Plant Science 9:203-209.

Wong,K.K.Y., L.U.L.Tan, and J.N.Saddler. 1988. Multiplicity of beta-1,4-xylanase in microorganisms: functions and applications. Microbiol. Rev. 52:305-317.

Zechel,D.L., and S.G.Withers. 1999. Glycosidase Mechanisms: Anatomy of a Finely Tuned Catalyst. Acc. Chem. Res. 33:11-18. 


\section{APPENDIX}

Table A.1. Bartlett's test for homogeneity of variance.

\begin{tabular}{lccc}
\hline Variance & DF & Chi-Square & Pr > Chi-Square \\
\hline Bran xylanase & 35 & 39.4 & 0.2808 \\
Flour xylanase & 35 & $118.2^{* * *}$ & $<.0001$ \\
Flour xylanase (Log transformed) & & $79.4^{* * *}$ & $<.0002$ \\
Whole meal xylanase & 35 & $56.9^{*}$ & 0.011 \\
Whole meal xylanase (Log transformed) & 35 & 43.5 & 0.1543 \\
Bran TAXI & 35 & 42.4 & 0.1832 \\
Flour TAXI & 35 & $67.1^{* * *}$ & 0.0009 \\
Flour TAXI (Log transformed) & 35 & $108.8^{* * *}$ & $<.0001$ \\
Bran XIP & 35 & 25.3 & 0.8857 \\
Flour XIP & 35 & 35.5 & 0.3548 \\
Bran AX & 35 & 27.2223 & 0.823 \\
Bran A/X ratio & 35 & 22.458 & 0.9501 \\
\hline
\end{tabular}

*** $P$-value $<0.0001 ; * P$-value $<0.05$ 
Table A.2. Location mean apparent xylanase activity, apparent TAXI activity and apparent XIP activity for 12 hard spring genotypes grown in Carrington, Casselton and Prosper, ND in 2008.

\begin{tabular}{|c|c|c|c|c|c|}
\hline \multirow[t]{3}{*}{ Genotype } & \multirow{2}{*}{\multicolumn{2}{|c|}{$\begin{array}{l}\text { Xylanase activity } \\
(\mathrm{mU} / \mathrm{g} \text { d. m. })\end{array}$}} & \multirow{3}{*}{$\begin{array}{l}\text { TAXI activity } \\
\text { (U/g d. m.) } \\
\text { Bran }\end{array}$} & \multicolumn{2}{|c|}{ XIP activity (U/g d. m.) } \\
\hline & & & & & \\
\hline & Bran & Whole meal & & Bran & flour \\
\hline Alsen & $\overline{11.9}$ & 3.3 & 1007.0 & 2967.6 & 1462.6 \\
\hline Briggs & 8.2 & 2.7 & 913.6 & 2533.1 & 887.9 \\
\hline Glenn & 10.0 & 2.6 & 834.0 & 2441.1 & 1452.1 \\
\hline Granite & 37.3 & 18.3 & 232.3 & 1946.9 & 964.6 \\
\hline Hanna & 12.2 & 6.5 & 646.3 & 2871.3 & 1454.8 \\
\hline Ingot & 3.0 & 2.5 & 742.7 & 3868.2 & 1373.6 \\
\hline ACSnow bird & 15.8 & 10.4 & 806.3 & 3570.7 & 1024.1 \\
\hline Explorer & 23.2 & 15.0 & 719.2 & 3231.0 & 1247.1 \\
\hline Lolo & 40.4 & 22.1 & 753.3 & 2586.6 & 734.2 \\
\hline CS3100Q & 30.1 & 14.1 & 769.3 & 2030.1 & 946.4 \\
\hline Pristine & 30.9 & 17.8 & 654.8 & 2718.6 & 1287.3 \\
\hline 99S0155-14W & 8.4 & 3.2 & 728.0 & 2813.7 & 873.8 \\
\hline $\operatorname{LSD}(5 \%)^{\mathrm{a}}$ & 3.6 & 1.6 & 58.6 & 488.1 & 129.6 \\
\hline
\end{tabular}

${ }^{\mathrm{a}} \mathrm{LSD}$, least significant difference. 